\title{
Guidance for a
}

Large Tabletop Exercise

for a Nuclear Power Plant

Manuscript Completed: December 1994

Date Published: March 1995

E. D. Weinstein, E. F. Bates,

M. V. Adler, ${ }^{*}$ K. S. Gant ${ }^{*}$

Office for Analysis and Evaluation of Operational Data

U.S. Nuclear Regulatory Commission

Washington, DC 20555-0001

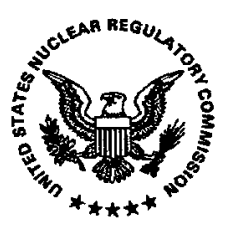

* Oak Ridge National Laboratory

Oak Ridge, TN 37831-6285 


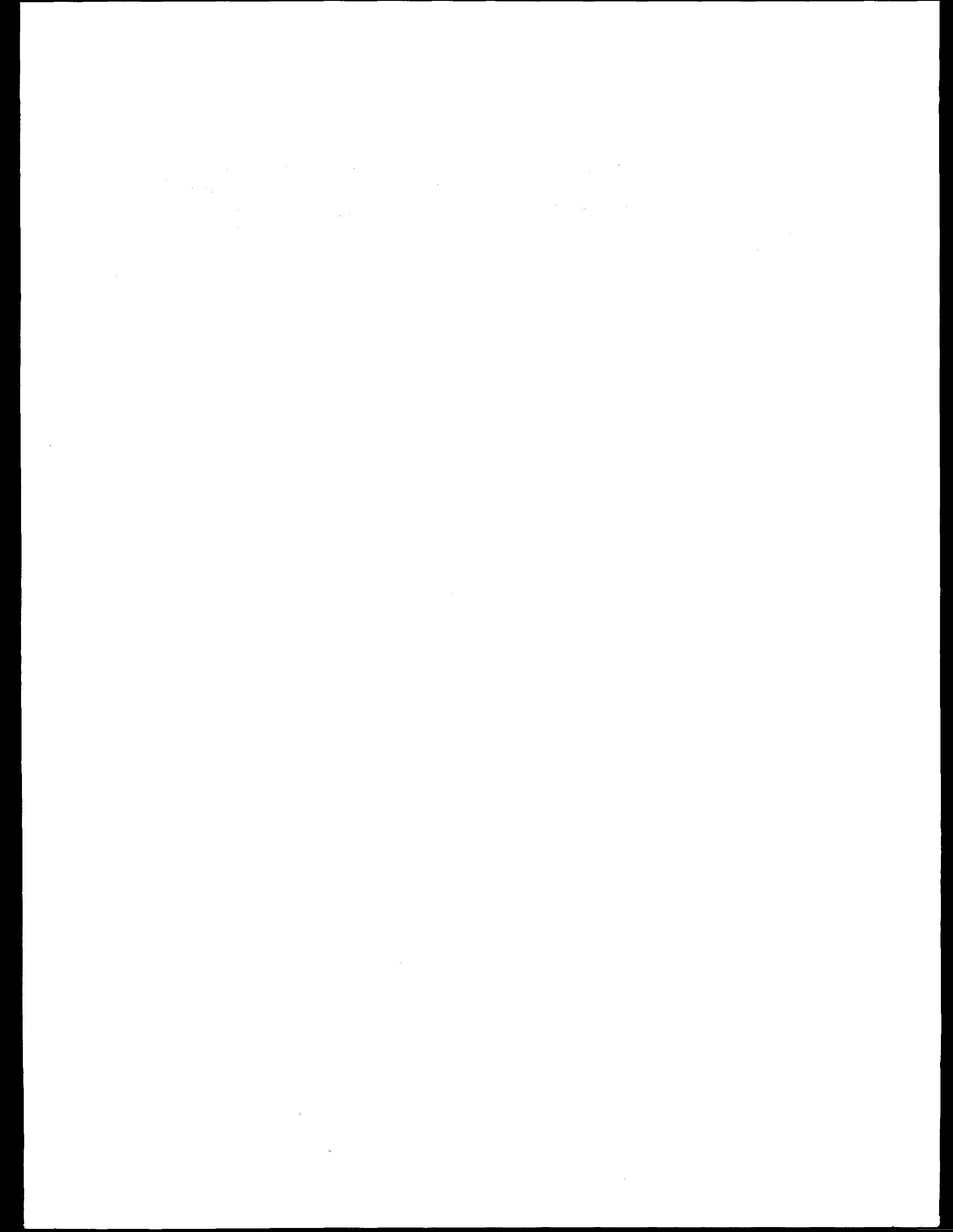




\section{DISCLAIMER}

This report was prepared as an account of work sponsored by an agency of the United States Government. Neither the United States Government nor any agency thereof, nor any of their employees, make any warranty, express or implied, or assumes any legal liability or responsibility for the accuracy, completeness, or usefulness of any information, apparatus, product, or process disclosed, or represents that its use would not infringe privately owned rights. Reference herein to any specific commercial product, process, or service by trade name, trademark, manufacturer, or otherwise does not necessarily constitute or imply its endorsement, recommendation, or favoring by the United States Government or any agency thereof. The views and opinions of authors expressed herein do not necessarily state or reflect those of the United States Government or any agency thereof. 


\section{DISCLAIMER}

Portions of this document may be illegible in electronic image products. Images are produced from the best available original document. 


\begin{abstract}
Tabletop exercises are held to discuss issues related to the response of organizations to an emergency event. This document describes in task format the planning, conduct, and reporting of lessons learned for a large interagency tabletop. A sample scenario, focus areas, and discussion questions based on a simulated accident at a commercial nuclear power plant are provided.
\end{abstract}




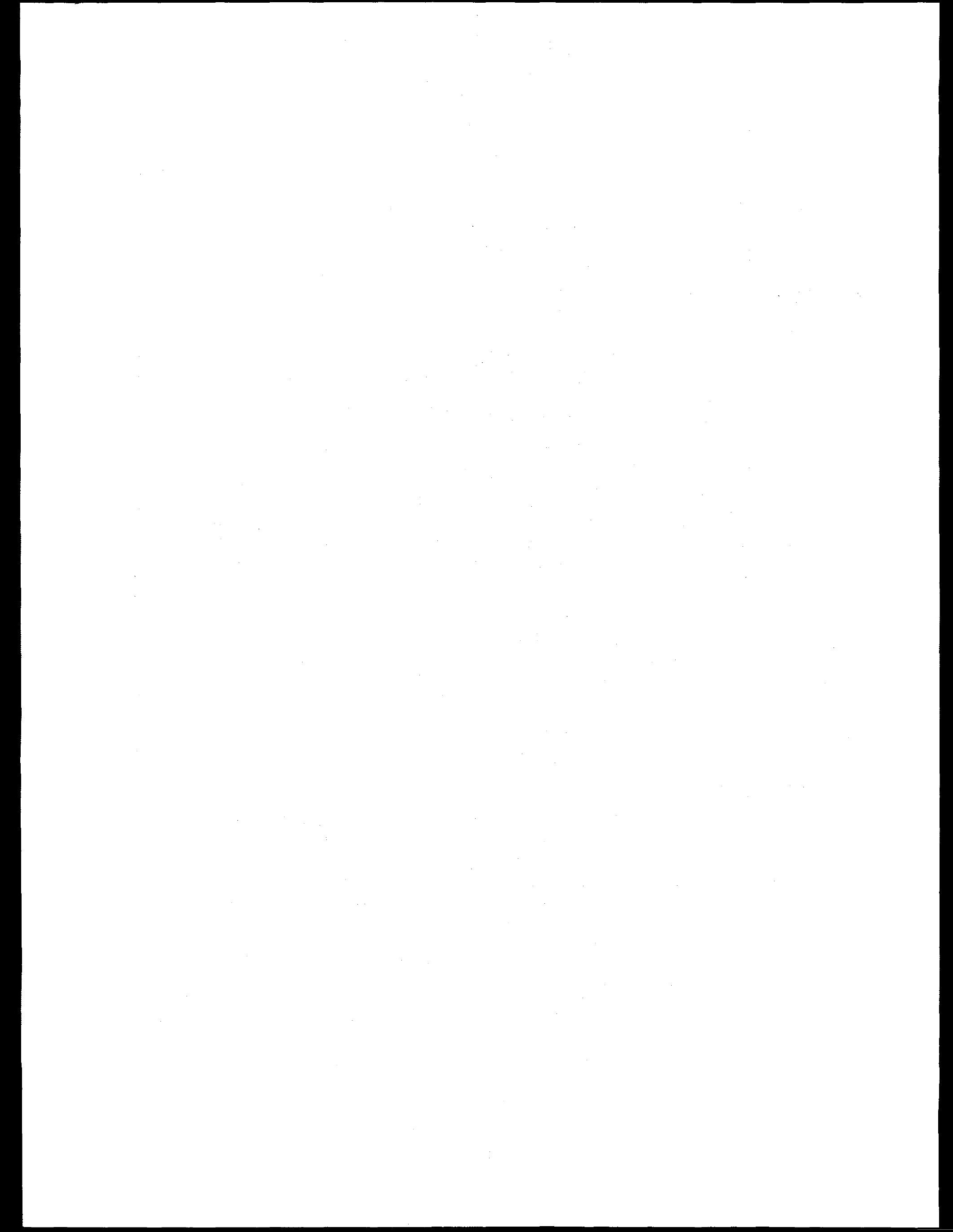




\section{CONTENTS}

Section

Page

ABSTRACT $\ldots \ldots \ldots \ldots \ldots \ldots \ldots \ldots \ldots \ldots \ldots \ldots \ldots \ldots \ldots \ldots \ldots$

ACKNOWLEDGEMENTS $\ldots \ldots \ldots \ldots \ldots \ldots \ldots \ldots$ vii

ABOUT THE AUTHORS $\ldots \ldots \ldots \ldots \ldots \ldots \ldots \ldots \ldots \ldots \ldots$

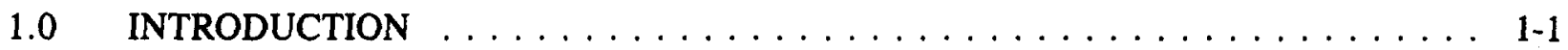

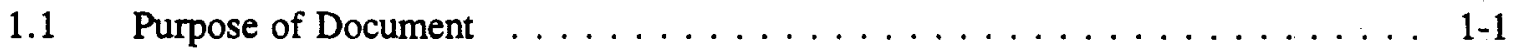

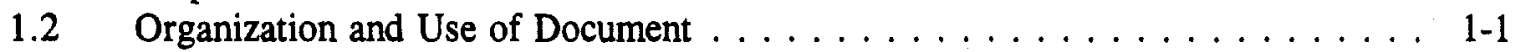

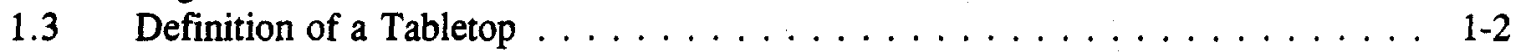

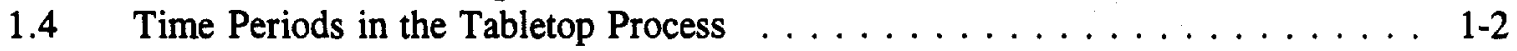

1.5 Participants in a Tabletop . . . . . . . . . . . . . . . . 1-2

1.5.1 Tabletop Coordinator . . . . . . . . . . . . . . 1-2

1.5.2 Tabletop Planning Committee . . . . . . . . . . . . . 1-2

1.5 .3 Players . . . . . . . . . . . . . . . . . . 1-3

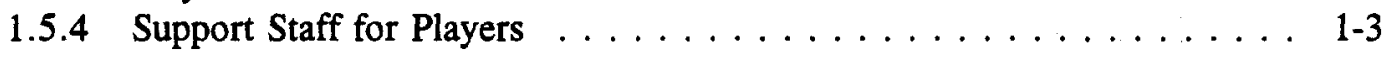

1.5 .5 Observers . . . . . . . . . . . . . . . . . . . 1-3

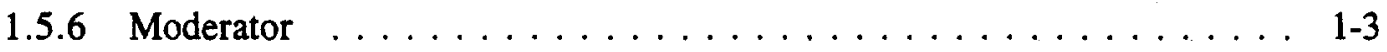

1.5 .7 Recorders . . . . . . . . . . . . . . . . . . . . . 1-4

1.5 .8 Tabletop Staff $\ldots \ldots \ldots \ldots \ldots \ldots \ldots \ldots \ldots \ldots$

1.6 Suggested Format for Tabletop $\ldots \ldots \ldots \ldots \ldots \ldots \ldots \ldots \ldots \ldots$

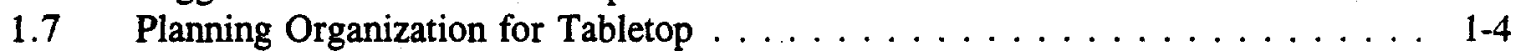

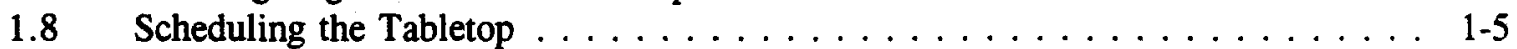

1.9 Summary of Information That Should Be Developed . . . . . . . . . . . . 1-5

1.10 Training Activities in Conjunction With Tabletop . . . . . . . . . . . 1-6

2.0 TASKS FOR PLANNING AND CONDUCTING THE TABLETOP AND

DETERMINING LESSONS LEARNED $\ldots \ldots \ldots \ldots \ldots \ldots \ldots \ldots \ldots \ldots \ldots$

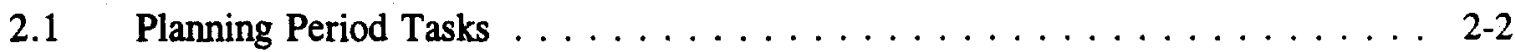

2.1.1 Task A - Initiate Planning for the Tabletop . . . . . . . . . . . 2-2

2.1.2 Task B - Determine Tabletop Date, Develop Planning Schedule and

Milestones, Coordinate Development of Tabletop Plan . . . . . . . . . . . 2-4

2.1.3 Task C - Develop Budget/Funding Plan . . . . . . . . . . . . . 2-8

2.1.4 Task D - Develop Focus Areas, Scenario; Choose or Develop

Preparatory Questions; Develop Supporting Visual Aids . . . . . . . . . 2-9

2.1.5 Task E - Develop Plan for Conducting Tabletop . . . . . . . . . . . . . 2-11

2.1.6 Task F - Develop Plan for Identifying and Reporting Lessons Learned . . 2-14

2.1.7 Task G - Develop Logistics Plan, Make Logistics Arrangements . . . . . 2-16

2.2 Conduct Period Tasks ... . . . . . . . . . . . . . . . . . 2-19

2.2.1 Task H - Provide Support Services to Participants . . . . . . . . . . 2-19

2.2.2 Task I - Conduct the Tabletop . . . . . . . . . . . . . . . 2-20 
2.3 Post-Tabletop Period Tasks . . . . . . . . . . . . . . . . . . 2-21

2.3.1 Task J - Determine Lessons Learned, Prepare Final

Report, Follow-up . . . . . . . . . . . . . . . . . 2-21

2.3.2 Task K - Complete Administrative Activities . . . . . . . . . 2-23

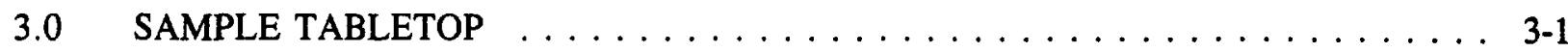

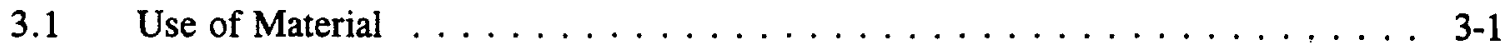

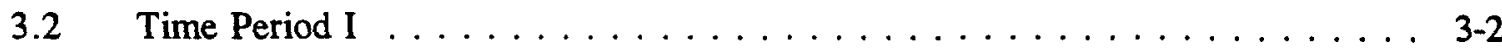

3.2.1 Focus Area 1 and Principal Questions . . . . . . . . . . . . 3-4

3.2.2 Focus Area 2 and Principal Questions ............ 3-4

3.2.3 Focus Area 3 and Principal Questions ... . . . . . . . . 3-4

3.2.4 Focus Area 4 and Principal Questions . . . . . . . . . . . 3-5

3.2.5 Related Preparatory Questions . . . . . . . . . . . . . . 3-5

3.3 Time Period II . . . . . . . . . . . . . . . . . . . . . 3-9

3.3.1 Focus Area 1 and Principal Question . . . . . . . . . . . . 3-10

3.3.2 Focus Area 2 and Principal Questions . . . . . . . . . . . 3-10

3.3.3 Focus Area 3 and Principal Questions . . . . . . . . . . . . . 3-10

3.3.4 Related Preparatory Questions . . . . . . . . . . . . . . 3-11

3.4 Time Period III . . . . . . . . . . . . . . . . . . . . . . . 3-13

3.4.1 Focus Area 1 and Principal Questions $\ldots \ldots \ldots \ldots \ldots$ 3-14

3.4.2 Focus Area 2 and Principal Questions . . . . . . . . . . . . 3-14

3.4 .3 Related Preparatory Questions . . . . . . . . . . . . . . . 3-14

\section{APPENDICES}

APPENDIX A - ACRONYMS AND INITIALISMS $\ldots \ldots \ldots \ldots \ldots \ldots \ldots \ldots$

APPENDIX B - LIST OF PUBLICATIONS THAT MAY BE USED AS REFERENCES . . . B-1

APPENDIX C - TABLES OF CONTENTS FROM TWO LESSONS LEARNED REPORTS . . C-1

APPENDIX D - RADIOLOGICAL INFORMATION FOR SAMPLE SCENARIO . . . . . . . D-1 


\section{ACKNOWLEDGEMENTS}

The authors would like to acknowledge the contributions of all the Federal agencies, State and local organizations, and utilities personnel who planned the Riverbend, Kewaunee, and Federal Field Exercise 3 tabletops, as well as those who participated in the major field exercises. Their experiences significantly helped to shape this document. 


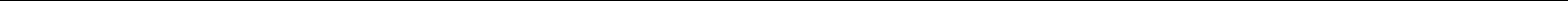




\section{ABOUT THE AUTHORS}

The authors of this document bring over 50 years of experience in planning for emergency response exercises to its preparation. They helped plan the major Federal Field Exercises (FFEs), FFE-1, FFE-2, and FFE-3 (cancelled before it was run) and their associated tabletops, as well as large tabletops, such as the Relocation Tabletop, Riverbend, and Kewaunee, run independently of field exercises. Members of the group contributed to major U.S. Nuclear Regulatory Commission (NRC) emergency preparedness documents and interagency response plans such as the Federal Response Plan and the Federal Radiological Emergency Response Plan.

Eric D. Weinstein is the State liaison for incident response at NRC headquarters in Rockville, Maryland.

Eugene F. Bates serves as the emergency response coordinator for the NRC Region IV, Arlington, Texas.

Kathy S. Gant and Martha V. Adler are on the research staff at the Oak Ridge National Laboratory, Oak Ridge, Tennessee. 
A disk copy of this document in WordPerfect 5.1 (Sections 1-3 and Appendices A and B) is available from Eric Weinstein, U.S. Nuclear Regulatory Commission, Mail Stop T-4A43, Washington, DC 20555-0001, (301) 415-7559. For further information contact Weinstein at (301) 415-7559. 


\subsection{INTRODUCTION}

\subsection{Purpose of Document}

This document provides a guide for planning and conducting a tabletop exercise (called "a tabletop" in this document) and for recording lessons learned. Information in this document could be used to plan a tabletop on any subject, but it is directed toward one based on interfaces among and activities of the agencies responding to an incident at a commercial nuclear power plant. The basic process is the same for large and small tabletops. Although the example used is for a large tabletop involving approximately 50 decision makers and their support staff, the information can be adapted to plan tabletops for smaller groups, for decision makers or initial responders, or for players at multiple locations.

\subsection{Organization and Use of Document}

The document is organized into three sections:

Section 1. Introduction. This section provides basic information on the purpose of the document and on tabletops: their organization, participants, information that must be developed, and possible training activities.

\section{Section 2. Tasks for Planning and Conducting the Tabletop and Determining Lessons}

Learned. The tabletop development process is separated into tasks which may be assigned to groups or individuals. The tasks are grouped according to the time period during which they are carried out (i.e., during the planning period, during the actual conduct of the tabletop, or in the post-tabletop period).

Section 3. Sample Tabletop. This section provides a sample tabletop scenario, focus areas, principal questions, and related preparatory questions. These questions can be used as is or adapted to the specific objective or location of the exercise. The tabletop may concentrate on all, or any subset, of the areas that are listed. The focus areas, with the principal questions relating to them, are used to guide the planning and conduct of the tabletop. The preparatory questions related to the focus areas may be used for training of players before the exercise. The object of the tabletop is to surface the issues and identify solutions based on agency plans and procedures.

Appendices to this report are

- Appendix A - Acronyms and Initialisms,

- Appendix B - List of Publications That May Be Used as References,

- Appendix C - Tables of Contents From Two Lessons Learned Reports, and

- Appendix D - Radiological Information for Sample Scenario. 


\subsection{Definition of a Tabletop}

A tabletop, as described here, is a structured discussion, which is based on a scenario or set of conditions for potential emergency response situations, among decision makers or responders in a low-stress environment. Tabletops are not intended to solve all problems or make policy; they may simply identify areas which need resolution. They are a teaching/training aid as well as an opportunity to talk through plans and procedures or discuss new systems. Their objective is both educational and developmental in that disconnects, perceptions, and procedures can be identified easily and then corrected.

\subsection{Time Periods in the Tabletop Process}

The tabletop process is divided into three time periods:

- the planning period, when a committee is organized and all decisions and arrangements are made regarding subject matter, participants, logistics, and lessons learned format;

- the conduct period, when the tabletop is actually conducted and the participants, using the material developed during the planning period, work through the problems presented in a scenario or set of conditions; and

- the post-tabletop period, when the participants and those conducting the tabletop assess what transpired, identify issues, and prepare a report.

\subsection{Participants in a Tabletop}

The following people/groups may be involved in the tabletop. When the term "participants" is used, it includes all personnel involved in the tabletop (e.g., planners, players, observers, and support staff).

\subsubsection{Tabletop Coordinator}

The tabletop coordinator is responsible for all aspects of the tabletop, chairs the planning committee, and oversees the conduct of the tabletop and preparation of the report. The tabletop coordinator usually initiates the planning for the tabletop, works with the moderator and recorders in preparing the final report, and compiles the materials to be kept for future reference.

\subsubsection{Tabletop Planning Committee}

The planning committee should have representatives from all of the major groups that will be playing. These representatives should have some decision-making authority for their groups, including the ability to commit financial resources within reason. The number on the planning committee is variable, but those groups whose input is needed on a routine basis should be represented. However, the committee should be small enough to work efficiently. Members of the planning committee generally are not players in the tabletop, but they are often useful as moderators or recorders. Some may participate as support staff to players. 


\subsubsection{Players}

Players participate in the tabletop in the roles they would expect to play during an emergency response. These roles should be identified either in organizational plans or procedures. The number of players may range from 5 to over 50 . The players chosen should have expertise in the topics to be discussed. For example, players from senior management might be addressing policy issues; or players who are members of technical teams might be analyzing a specific problem. The players should be familiar with the position they will play and be able to speak for their organizations. Players for a tabletop dealing with a power reactor accident may include

- State and local government representatives;

- nuclear industry representatives [utility, American Nuclear Insurers/Mutual Atomic Energy Liability Underwriters (ANI/MAELU)]);

- Federal representatives, including but not limited to regional and headquarters representatives from the U.S. Nuclear Regulatory Commission (NRC) and other appropriate Federal representatives [e.g., U.S. Department of Energy (DOE), U.S. Department of Agriculture (USDA), U.S. Department of Health and Human Services (HHS), U.S. Department of the Interior (DOI), U.S. Environmental Protection Agency (EPA), U.S. Department of Defense (DOD), and Federal Emergency Management Agency (FEMA). Seventeen Federal agencies are signatories of the Federal Radiological Emergency Response Plan (FRERP) and 27 agencies plus the American Red Cross, have signed the Federal Response Plan (FRP)]; and

- persons who could discuss special concepts and procedures, such as technical experts in related fields.

\subsubsection{Support Staff for Players}

In some tabletops in which high-level decision makers are players, the decision makers may wish to have some of their support staff to assist them. The number of support staff should be limited.

\subsubsection{Observers}

Observing a tabletop can be valuable training for staff and persons from other regions or headquarters. Observers are non-playing persons, seated in a special area during the conduct of the tabletop, who watch and listen to the players. Observers do not actively participate but may be allowed to submit written questions or comments in a limited fashion which will be used at the moderator's discretion. Careful consideration should be given to the selection of observers and the way in which they will interact with tabletop players.

\subsubsection{Moderator}

The moderator(s) conducting the tabletop should be skilled in leading a discussion and familiar with the issues being explored. The moderator will guide the players through the 
scenario and elicit information from them on their anticipated response during the conduct of the tabletop. The moderator provides significant input to planning, conduct, and the final report and is critical to the success of the tabletop. A back-up moderator should always be identified early in the planning phase of the tabletop and included in the training. During the tabletop, the back-up moderator assists in keeping the tabletop on track and on schedule.

\subsubsection{Recorders}

Recorders make notes on the discussions that occur during the conduct of the tabletop, noting areas of agreement, disagreement, and where clarification is needed. Observation forms may be provided to the recorders and can be used in structuring the final report. The recorders frequently are members of the planning team and may represent the agencies or groups participating. The moderator(s), recorders, and exercise coordinator are principal contributors to the final report.

\subsubsection{Tabletop Staff}

Staff will be needed before, during, and after the tabletop for activities such as making logistic arrangements, typing, preparing packets of material and final reports, room setup, and possibly registering participants. These persons usually come from the sponsoring organization.

\subsection{Suggested Format for Tabletop}

The tabletop described in this document is planned by members of the participating groups/agencies. It is conducted as a guided discussion in a question/answer format led by a moderator. The time period may range from an hour to a full day or more. The players should be knowledgeable and prepared. They should receive information on the focus areas, scenario, and preparatory questions before the tabletop. Players are seated at one or more tables so that they can see each other and the moderator. The moderator sets the stage with any necessary background information on the location of the accident and the initiating event and then interactively leads the group through their response to the scenario events. Visual aids are available to supplement the moderator's information but are not required. The tabletop may be structured by time period or topic. Recorders capture the information from the discussion. After the tabletop, there is a self-assessment by the players, followed by a meeting of the tabletop coordinator, moderator, and recorders to identify issues and prepare a draft report. A final report is distributed to participants and other interested parties. A target date of 3-6 months after the tabletop should be the goal for distributing the report. Additional time will diminish the effectiveness.

\subsection{Planning Organization for Tabletop}

The planning necessary for the tabletop will depend on its size and complexity. The planning organization must be tailored to each tabletop. The planning activities in this document are laid out by time period in task format. However, the person or group taking responsibility 
for one task or portion of a task must work closely with other planning committee members to ensure all aspects of the overall planning are coordinated.

\subsection{Scheduling the Tabletop}

There are no hard and fast rules for scheduling a tabletop, and the constraints will depend on whether it is interagency or intra-agency and the types of players expected to attend. The expected participants must have some input into the scheduling process. State groups, in particular, need as much lead time as possible. In general, a six-month lead time for conducting all planning activities is adequate. Some factors that should be considered in developing the initial time-window and final date chosen for an interagency tabletop are

- scheduled nuclear power plant regulatory exercises involving State, Federal, and utility representatives;

- length-of-notice required for out-of-State travel for State and local personnel;

- State legislative sessions (some State officials find it difficult to travel while the State legislature is in session);

- State and Federal budget process;

- local, State, and Federal elections;

- other scheduled exercises;

- holidays, especially the Thanksgiving and Christmas periods in relation to the planning process; and

- availability of a facility in which to hold the tabletop.

\subsection{Summary of Information That Should Be Developed}

Whether the tabletop is small or large, some written materials will be developed and their distribution should be tracked. A list of these materials, arranged by the time period in which each part is developed, and the task under which each is developed or coordinated is given below. The tabletop coordinator will be responsible for seeing that the appropriate material is developed and filed for future use.

Planning Period (material is listed in approximate order of development)

- Exercise scope (developed in Task A, Section 2.1.1);

- Tabletop goals or objectives (developed in Task A, Section 2.1.1);

- Planning schedule and milestones for tabletop (developed in Task B, Section 2.1.2);

- Budget and funding information (developed in Task C, Section 2.1.3);

- List of participants (developed in Task E, Section 2.1.5);

- Tabletop plan (TTPLAN) (coordinated under Task B, Section 2.1.2);

- Focus areas, scenario, and preparatory questions; supporting visual aids (developed in Task D, Section 2.1.4);

- Final report format (developed in Task $F$, Section 2.1.6);

- Logistic information: meeting place, lodging for out-of-town participants (developed in Task G, Section 2.1.7); 
- Registration forms, memos/letters of invitation (developed in Task G, Section 2.1.7);

- Contracts for use of facilities, equipment (developed in Task G, Section 2.1.7);

- Information to be given to players before exercise (developed in Task E, Section 2.1.5);

- Information to be given to moderators before the exercise (compiled under Task $E$, Section 2.1.5);

- Information to be given to recorders before the exercise (compiled under Task E, Section 2.1.5);

- Participants' briefing (developed in Task E, Section 2.1.5);

- Participants' comment forms (developed in Task F, Section 2.1.6); and

- Minutes of planning meetings (assigned by Exercise Coordinator). Minutes of each planning meeting should be kept. For a large tabletop with subgroups, distribution of the minutes to members of other groups is an important way to keep the planning coordinated.

\section{Conduct Period}

- Recorders' notes (developed in Task I, Section 2.2.2).

Post-tabletop Period

- Final report (developed in Task J, Section 2.3.1); and

- File of information on tabletop for future reference and archives (completed in Task $K$, Section 2.3.2).

\subsection{Training Activities in Conjunction With Tabletop}

The tabletop may be a stand-alone activity or held in conjunction with a workshop that would cover other material. Preparation for the tabletop exercise can include asking the players to review pertinent plans and procedures and to think through the preparatory questions relating to the focus areas that will be covered. 


\subsection{TASKS FOR PLANNING AND CONDUCTING THE TABLETOP AND DETERMINING LESSONS LEARNED}

The process for planning and conducting the tabletop and determining the lessons learned has been divided into three time periods: planning, conduct, and post-tabletop.

Tasks are identified for each time period. Activities are listed under each task. Additional explanatory information (e.g., suggested meeting agenda or the contents of material to be developed) is given following the task checklist. An individual or a group may be assigned to a section or an entire task. Many of the tasks during the planning period will be worked on concurrently; some of the information will be used in subsequent periods.

\section{SUMMARY OF TASKS BY TIME PERIOD}

\section{Planning Period}

Task A - Initiate planning for the tabletop (Section 2.1.1)

Task B - Determine tabletop date, develop detailed planning schedule and milestones, coordinate development of the TTPLAN (Section 2.1.2)

Task C - Develop budget/funding plan (Section 2.1.3)

Task D - Develop focus areas, scenario; choose/develop preparatory questions; develop supporting visual aids (Section 2.1.4)

Task E - Develop plan for conducting tabletop (Section 2.1.5)

Task F - Develop plan for identifying and reporting lessons learned (Section 2.1.6)

Task G - Develop logistics plan; make logistics arrangements (Section 2.1.7)

\section{Conduct Period}

Task H - Provide support services to participants (Section 2.2.1)

Task I - Conduct the tabletop (Section 2.2.2)

Post-Tabletop Period

Task J - Determine lessons learned, prepare report, follow-up (Section 2.3.1)

Task K - Complete administrative activities (Section 2.3.2) 


\subsection{Planning Period Tasks}

\subsubsection{Task A - Initiate Planning for the Tabletop}

The initial planning for a tabletop can come about in several ways, depending on the expected number of participants and the organization. The following steps set the framework for the tabletop. Preparatory work by the tabletop coordinator will decrease both planning time and the number of exploratory meetings required.

\section{CHECKLIST OF TASK A ACTIVITIES}

Appoint tabletop coordinator.

Make initial phone calls.

Organize planning committee.

Hold initial meeting.

Develop scope of exercise.

Develop goals and objectives.

Get appropriate approvals.

\section{COMMENTS}

Tabletop coordinator: The tabletop coordinator usually has exercises and training as part of his/her job responsibility. The coordinator may initiate the tabletop activity (often as part of a regularly scheduled program), or senior management may request that a tabletop be held.

Initial phone calls: Tabletop coordinator makes calls to determine interest, topics for exercise, time window for holding tabletop. If organizations other than the coordinator's are to be involved, they should participate in the initial planning.

Planning committee: The tabletop coordinator asks appropriate people to serve on the planning committee based on the preliminary responses to his/her inquiries regarding the tabletop. The planning committee should include representatives of the participating groups/organizations and be small enough to work efficiently. A planning committee directory containing names, affiliations, addresses, phone and fax numbers, and electronic mail addresses should be developed and distributed. 


\section{Suggested agenda for initial meeting:}

- development of a proposed scope (including suggested date or time window) for the tabletop;

- discussion of the purpose of the tabletop and possible format and duration;

- discussion of goals and objectives for tabletop, including organization-specific objectives;

- initial discussion of organization and determination of lessons learned for tabletop, tasks, general planning schedule, and preliminary assignments; and

- date for next meeting.

Tabletop scope: The planning committee should develop a short (usually one or two paragraphs) description (called a scope) for the tabletop. The scope can be used by the participating groups/agencies to get appropriate approvals for their participation. The scope should include

- form of tabletop (e.g., discussion group with moderator);

- topic of the tabletop (e.g., initial activation; protective measures analysis; reentry, return, and recovery);

- organizations/groups playing, and

- approximate date and location of the tabletop.

Tabletop goals and objectives: The tabletop goals and objectives are an amplification of the topic of the exercise. Topics to be covered, who should play, and what the participants are expected to accomplish from the tabletop should be agreed upon initially. From this agreement, a scenario can be developed or adapted and appropriate focus areas and preparatory questions chosen to both help players prepare for the tabletop and assist the moderator in facilitating the discussion.

Approvals for tabletop: Following the initial meeting, the members of the planning committee can obtain the appropriate approvals from their managements. The approvals should be procured as rapidly as possible so planning can progress smoothly. 


\subsubsection{Task B - Determine Tabletop Date, Develop Planning Schedule and Milestones, Coordinate Development of Tabletop Plan}

Members of the planning committee are usually responsible for these activities. The planning schedule drives many of the other tasks since Task B activities incorporate information developed in other tasks.

\section{CHECKLIST OF TASK B ACTIVITIES}

Establish firm date for tabletop (see Section 1.8 for information on selecting date for tabletop).

Develop planning schedule and milestones for tabletop.

Assign responsibilities for tasks and activities to organizations/individuals.

Assure development and compilation of TTPLAN.

\section{COMMENTS}

Tabletop plan: A comprehensive TTPLAN is most useful for large tabletops, but in modified form, a plan should be used for all tabletops. The information in the plan is developed under different tasks, but its compilation should be assigned to one person. The TTPLAN provides detailed information and includes

- participants (often by name) (developed in Task E, Section 2.1.5);

- exercise location (developed in Task G, Section 2.1.7);

- objectives or goals of the exercise (developed in Task A, Section 2.1.1);

- format for the exercise (developed in Task A, Section 2.1.1, and Task E, Section 2.1.5);

- how lessons learned will be developed (developed in Task F, Section 2.1.6);

- persons/groups assigned responsibilities (developed in Task B, Section 2.1.2);

- ground rules for the tabletop (developed in Task E, Section 2.1.5);

- type of final report expected (discussed in Task A, Section 2.1.1; format developed in Task $F$, Section 2.1.6);

- scenario, focus areas, preparatory questions (developed in Task D, Section 2.1.4), usually included as an appendix; and

- list of abbreviations.

Planning schedule and milestones for tabletop: An overall planning schedule (usually covering three to four months for not-too-complex exercises with a limited number of groups/participants, six to eight months for a large interagency tabletop) should be developed early in the planning process. The schedule should include adequate time for approvals, any contracts that are necessary, review of materials, mail delivery, etc. The planning group should determine meeting schedules. Conference calls are a useful tool. A large interagency tabletop may be combined with a program of introductory or supplemental material in a 
workshop. A sample schedule for a large interagency tabletop follows. Activities are listed in approximate chronological order. Meetings are held as needed in each time period. This schedule could be adapted for a tabletop combined with a workshop.

\section{PLANNING PERIOD}

Six months before tabletop (or workshop), the organizers should

- define general objective(s);

- get approval from host organization (region, headquarters);

- designate coordinator;

- make preliminary inquiries of potential playing agency participants regarding interest in and time window for tabletop;

- determine how organizations' participation will be funded;

- determine general budget and whether a small registration fee will be needed for refreshments and incidentals;

- convene planning group; and

- determine appropriate organizational level of players.

Five months before the tabletop, the planners should

- $\quad$ set final date if initial date was tentative;

- make initial inquiries for meeting rooms, other logistic arrangements;

- agree on goals or objectives;

- review and consolidate organizations' objectives;

- invite specific players (workshop speakers) by telephone with follow-up letter; and

- draft general letters of invitation to observers and other participants, draft registration forms (if needed), and draft proposed agenda.

Four months before the tabletop, the planners should

- make final arrangements for meeting room(s);

- reserve block of hotel rooms, if needed for out-of-town participants;

- try to find a sponsor for an evening reception or other planned social event if the tabletop (workshop) is very large and attended by many out-of-town participants;

- designate moderator(s), back-up moderator, and recorders;

- send formal letters of invitation to participants; include proposed program, information on travel, housing, meals, and registration form;

- develop or adapt scenario, focus areas, principal and preparatory questions; and

- develop plan for conduct of tabletop, including plan for observers.

Three months before the tabletop, the planners should

- have final list of attendees and alternates;

- invite senior staff member of host organization (e.g., NRC) to make introductory remarks and welcome participants; and 
- complete scenario, any necessary data preparation (may require discussion with State or utility officials), and preparatory questions.

Two months before the tabletop, the planners should

- complete TTPLAN;

- $\quad$ send appropriate materials to participants (focus areas, objectives, preparatory questions, any additional information on agenda, housing, arrangements, funding) (organizations may wish to consider using the focus areas and preparatory questions for training players before the tabletop); and

- prepare and reproduce comment form for participants to complete after tabletop or workshop.

One month before the tabletop, the planners should

- mail out any final information to participants (provide emergency or message telephone number if known);

- make logistical arrangements for registration, setting up meeting room, audio-visual equipment, refreshments for breaks and any social functions;

- prepare and reproduce any handouts;

- draft final agenda (program); and

- brief moderator(s) and recorders.

Two weeks before the tabletop, the planners should

- (if workshop) assign participants to groups if necessary

One week before the tabletop planners should

- reconfirm availability of key participants (participant lists are not final until the day of the tabletop!).

Three days before the tabletop, the planners should

- type and reproduce final program or agenda. (If only a tabletop is run, this can be done earlier. If the tabletop is combined with a workshop, there may be changes up until the last few days. A simple, accurate program is preferable to a more elaborate one that cannot accommodate late changes.);

- reconfirm logistical arrangements for registration, availability and setting-up of meeting room and audio-visual equipment, refreshments for breaks, any social functions; and

- reconfirm availability of senior official if one has been scheduled to make opening remarks. 


\section{CONDUCT PERIOD}

During the tabletop, planners should

- act as welcoming hosts to participants;

- provide staff to help participants with travel, expense information, reproduction of materials, etc.;

- provide needed handouts;

- distribute comment forms at final break; and

- back-up moderator encourages moderator (and speakers if a workshop) to stay on schedule.

\section{POST-TABLETOP PERIOD}

Immediately following the tabletop, the moderator

- conducts a post-tabletop debriefing by the players on lessons learned;

- collects comment forms; and

- meets with the tabletop coordinator and recorders (usually the following day) to identify issues and prepare draft report.

Post-tabletop, the tabletop coordinator

- distributes draft report (if interagency tabletop) for comment, then prepares and distributes final report within six months;

- writes appropriate thank you letters and sends certificates of participation if appropriate;

- does final accounting work; and

- makes file for future reference.

As time permits, the participants should make necessary modifications to their plans and procedures based on the tabletop lessons learned. 


\subsubsection{Task C - Develop Budget/Funding Plan}

\section{CHECKLIST OF TASK C ACTIVITIES}

Agree on how exercise is to be funded and determine sources of funds.

Develop budget for exercise.

Decide on registration fee and amount.

Send budget and funding information to appropriate participants.

\section{COMMENTS}

Budget and funding information: The planning committee develops the budget. The tabletop coordinator ensures that the tabletop stays within budgeting limits. The budget may include items such as travel costs for host agency participants from other areas, cost of a meeting room, additional staff time, supplies (such as handouts, name tags), postage, and any refreshments, lunch, social events, and certificates or mementos. A small registration fee is frequently charged to defray costs of refreshments and lunch. Consider assigning a tracking/accounting system number for staff time used in tabletop activities. Staff time can be minimized, when appropriate, by using or adapting the scenario given, along with the preparatory questions, rather than developing a new scenario. A major expense and one of the biggest unknowns is budgeting for travel expenses for organizations with spending limits. Representatives from Federal agencies are usually expected to fund their own participation. 


\subsubsection{Task D - Develop Focus Areas, Scenario; Choose or Develop Preparatory Questions; Develop Supporting Visual Aids}

\section{CHECKLIST OF TASK D ACTIVITIES}

Review the goals/objectives of the exercise.

Develop/adapt material on focus areas based on goals/objectives of exercise.

Develop/adapt the scenario.

Prepare visual aids.

Choose or develop preparatory questions.

Coordinate overall schedule for tabletop with time needed for discussion of each focus area topic.

\section{COMMENTS}

Developing focus areas and adapting the scenario: The focus areas and scenario will reflect the objectives of the exercise. Section 3 contains a sample scenario for an emergency at a commercial nuclear power plant. The scenario has been divided into time periods. Within each time period, several focus areas have been identified to provide a basis for the discussion. Each focus area has several principal questions listed, which guide the discussion. The planners should choose or adapt focus areas which correspond to the areas of interest (goals/objectives) for the tabletop. There should be input from representatives of the playing organizations when the material is developed, and adequate time should be allowed for discussion of each topic.

The sample scenario, if used, should be adjusted to fit the local conditions and focus areas of exercise. For example, the name of the power plant and surrounding counties and states can be inserted. In the scenario in Section 3, the initiating event is described. If the tabletop focus is on activities later in an accident, information on the agencies notified would be in the initial information given to the players. If the tabletop is to discuss notification, no information would be given on who would be notified; that would be a topic of discussion. In the sample scenario given, the play of the tabletop begins at declaration of the site area emergency. However, in a tabletop, play can start at any time and with any topic. Enough radiological and meteorological data and realistic information on previous activities of individuals and groups must be supplied to all players to provide realism and a basis from which to start. In a tabletop, technical data which must be manipulated or calculated are usually not needed. Input from the response organizations is very important in establishing the scenario's authenticity. 
Preparing visual aids: Prepare any diagrams, maps, and slides needed for the scenario. Suggested visual aids are listed in Section 3. Only the information needed should be provided because extraneous information may distract players from the purpose of the tabletop. Experience indicates that the more technical or complex the material, the less it will be used.

Developing preparatory questions: Planners may prepare their own questions or, when appropriate, adapt those listed in Section 3. The questions should be adapted to the local situation. Questions may be sent to the players and used by them to prepare for the tabletop.

Time allotments for tabletop focus areas: The planners should not try to cover too much material during the tabletop. A limited number of focus areas and questions will allow for indepth discussion. Time must also be allotted for activities in addition to the focus area discussions. For example, in a day-long tabletop ( 8 a.m. to 5 p.m.), the schedule should include

1 hour welcome by host organization, introduction of participants, briefing of players, introduction of scenario and initial focus area. (Approximately $\mathbf{5}$ minutes should be budgeted for introduction and 5 minutes for a summary when discussion is concluded for each focus area.)

1 hour for break times (20 minutes to half hour per break). Breaks are recommended in the morning, afternoon, and post-exercise (before debriefing to allow players/moderator time to prepare comments)

1 hour lunch (if lunch is available in room; otherwise, if participants must go elsewhere for lunch, allow 1.5 hours)

\section{5 hour debriefing}

The above totals 3.5 hours, plus 10 minutes for introducing each additional focus area. The remaining time (5.5 or fewer hours) should be divided among the focus areas. The amount of time available for discussion of each question within each focus area should be calculated. (For example, if there are 5 focus areas, there would be approximately 1 hour for each. If each focus area had 5 questions, there would be approximately 12 minutes for discussion of each question.) The number of focus areas and questions may need to be adjusted to allow adequate time for discussion within the time available. 


\subsubsection{Task E - Develop Plan for Conducting Tabletop}

\section{CHECKLIST OF TASK E ACTIVITIES}

Identify and develop list of participants

_ Host agency representative (to welcome group),

Players and players' support staff (see Sections 1.5.3 and 1.5.4),

_ Observers (see Section 1.5.5),

_ Moderator(s), back-up moderator (see Section 1.5.6),

Recorders (see Section 1.5.7; recorders are identified in Task F, Section 2.1.6),

_ Tabletop staff (see Section 1.5.8; identified in Task G, Section 2.1.7).

Agree on format for tabletop, including conduct of tabletop and observer activities.

Develop agenda for tabletop (coordinate with Task D, Section 2.1.4).

Develop ground rules for tabletop.

Develop guidance for moderator(s).

Determine arrangement of meeting room.

Determine information to be given to players and other participants in advance (coordinate with Task D, Section 2.1.4; Task F, Section 2.1.6; and Task G, Section 2.1.7).

Develop briefing for participants to be given day of tabletop.

\section{COMMENTS}

List of participants (See Section 1.5): The list of participants, arranged according to their role in the tabletop (e.g., player, moderator) should include name, title, organization, address, and telephone and fax numbers. Initially it may be possible to have a single contact for each agency playing (who may be a member of the planning committee). As the tabletop draws closer, more exact lists can be developed. A final list of attendees should be prepared and distributed at the tabletop. 
Exercise format: Several formats are possible for tabletops. The one described in Section 3 uses a moderator who asks pertinent questions based on a scenario to elicit answers and discussion. Other tabletops may be conducted by giving the participants a scenario problem and then asking them to solve it. Players may be seated around a table or seated at separate tables according to organization or function. Agreement early in the planning on the basic format is important in order to develop appropriate material for the moderator.

Exercise agenda: See Task D, Section 2.1.4 for specifics on time allotments. When the agenda is developed, include adequate time for registration and the preliminary conversations among people who do not see each other frequently, realistic breaks (at least 20 minutes each) and lunch period, and ample time for a post-tabletop players' self-assessment. Bringing in lunch and having refreshments in the room will minimize time lost.

Exercise ground rules: The ground rules will vary with the format for the tabletop. In the moderator-led tabletop, basic ground rules include

- courtesy;

- one person talks at a time, no side conversations unless consultation with staff is needed;

- wait for recognition to speak if not addressed directly;

- an up-front agreement on whether issues are to be discussed with the goal of reaching a solution or if issues are to be identified and resolved later (this is the recommended approach considering the limited time available in a typical tabletop); and

- observers do not participate in the tabletop. If agreed on in advance, observers may submit written questions or comments which will be used at the moderator's discretion.

Guidance for moderators: The moderator(s) should receive the same information as the players plus guidance on the role of the moderator and any special information the planners think would be useful. The moderator should ensure that the discussion reflects the focus areas and goals and objectives of the tabletop (coordinate with Task D, Section 2.1.4).

Exercise room set-up: Determine arrangement for room and audio-visual requirements (e.g., push-to-talk microphones, projectors). The moderator should be clearly visible to all, and the players should be seated at tables and able to see each other easily. Support staff may be seated close to or behind the players. Observers should be seated in one designated section, where they have a clear view of the moderator and any visual aids used. Table tents for each player with name and organization in letters large enough to be read are a great help. Amplification is recommended (with push-to-talk microphones) for tabletops with more than 30 people in attendance.

Advance information for players: Players and support staff should receive information on the exercise far enough in advance to study the preparatory questions and do any research necessary. Preparation of letters of invitation and sending of packets is discussed in Task G, Section 2.1.7. The following information should be given to the players:

- the TTPLAN (compiled under Task B, Section 2.1.2);

- agenda for the tabletop (developed in Task E, Section 2.1.5); 
- logistic information for participants who do not live in the area (developed in Task G, Section 2.1.7);

- telephone contact number for participants during tabletop;

- any other tabletop-specific information; and

- references, if needed (see Appendix $B$ for possible references).

Briefing for participants: All participants should be briefed on the day of the tabletop. The briefing can include

- welcome by senior representative of host organization;

- brief introduction giving name and role in tabletop of all players, moderators, and recorders;

- routine housekeeping information (time of breaks, location of rest rooms, message board, phones);

- information on the purpose of the tabletop;

- ground rules, role of recorders and observers;

- how lessons learned will be developed and the process for the final report;

- the players debriefing following the tabletop, and availability of comment forms.

The moderator sets the stage for the tabletop by giving background information on the location and initiating event of the scenario. 


\subsubsection{Task F - Develop Plan for Identifying and Reporting Lessons Learned}

\section{CHECKLIST OF TASK F ACTIVITIES}

Designate person (lead recorder) responsible for developing plan for identifying and reporting lessons learned, assuring that report reflects the goals and objectives of the tabletop, and developing and adhering to a schedule to issue reports in a timely fashion.

Agree on content and format of final report.

Determine number and qualifications of recorders needed; identify recorders.

Assemble and distribute material for recorders.

Develop participants' comment forms.

Brief moderator and recorders.

\section{COMMENTS}

Lead recorder: The person chosen as lead recorder may be the tabletop coordinator or his/her designee. The person will coordinate the planning for determining lessons learned from the tabletop and the compilation of the draft and final reports.

Final report: The outline and schedule for issuing the lessons learned report, including the format for identifying issues and suggestions for corrective action, should be decided on before the tabletop. For an interagency tabletop, the participating agencies should agree in advance on how the tabletop is to be assessed and the form for the report. The final report should clearly identify major lessons learned and be issued within six months to assure maximum effect. The tables of contents for two large interagency tabletops are reproduced in Appendix $\mathrm{C}$. In general the report includes the following as a minimum:

- executive summary;

- background information on tabletop (who, what, where, when);

- purpose, goals, and objectives of tabletop;

- list of participants [moderator(s), recorder, players with title and organization];

- lessons learned: for each focus area, lessons learned may be reported in a format of observation, recommended action relating to the observation; and organization(s) responsible for implementing the action, and

- any agreements reached on follow-up actions.

Recorders: Several recorders may be needed. Each organization may wish to have its own recorder. The recorders should be familiar with the topics to be discussed. Members of the planning committee are good candidates for recorders. 
Information for recorders: The recorders should receive the same information as the players and any special instructions regarding their responsibilities as recorders. In addition, provide copies of response plans, if appropriate, for the recorders to review in advance.

Participants' comment forms: Participants' written comments should be solicited on both lessons learned from the tabletop discussion and on the mechanics and logistics of the tabletop. A standard form should be prepared in advance. The comment forms will differ for each tabletop depending on the type of information desired. For example, planners may wish to know whether the participants found the experience useful and, if so, what major lessons were learned. Identification of issues that were overlooked, comments on the logistic arrangements, or suggestions for future tabletop subjects may also be appropriate.

Briefing for moderator, recorders: The moderator should be thoroughly familiar with the material and, if possible, be included in the planning or be briefed well in advance of the tabletop on the discussion areas. The moderator and recorders should be briefed shortly before the tabletop on what is expected from them. Recorders may be given forms to use for ease in structuring the lessons learned report. 


\subsubsection{Task G - Develop Logistics Plan, Make Logistics Arrangements}

\section{CHECKLIST OF TASK G ACTIVITIES}

Determine logistic requirements (e.g., meeting rooms, refreshments, lodging, transportation, audio-visual).

Make arrangements for room and audio-visual equipment.

Develop logistic information for out-of-town participants.

Write letters of invitation and compile packets of information to be sent to participants (coordinate with Task E, Section 2.1.5).

Develop registration forms, if needed; plan for registration, including tabletop staff to assist.

Order certificates and mementoes, if appropriate.

Negotiate necessary contracts and arrangements for use of facilities.

Arrange for refreshments and lunch.

Arrange for facility access and badges, if needed; prepare name tags and name tents for tables.

Set up room (coordinate with Task E, Section 2.1.5).

\section{COMMENTS}

Logistic requirements: All groups involved in the planning of the tabletop should determine their logistic requirements and tell the person or groups responsible for making arrangements. For example, the planners will know approximately how many people will be attending. This influences the size of the room needed and voice amplification requirements, lodging requirements, and refreshments and lunch.

Equipment: The following equipment may be required: wireless lapel and push-to-talk microphones (for the moderator and players respectively), projection equipment (usually an overhead projector) and screen, and, possibly, access to a reproduction machine, personal computer, and fax machine. White boards or flip charts may be needed. A board for posting messages for the participants and other information is useful.

Lodging, use of hotel meeting rooms: If there are out-of-town participants, a block of rooms is usually reserved at a convenient hotel with rates within the allowance of all participants. The rooms are held until a specified date, and participants are expected to make their own reservations. The hotel should have adequate parking, shuttle service or 
convenient, reasonably priced transportation to the airport, and a restaurant in the hotel or very close and reasonable access to other eating establishments. Complimentary breakfasts, available at many hotels, are always popular with travelers. If a block of rooms is reserved, the hotel may provide a meeting room for the tabletop without charge.

Letters of invitation, information for out-of-town and other participants: Participants in a large tabletop should be sent letters of invitation which provide information on the who, what, where, why, and funding. A registration form may be included. Packets of information should be sent to all participants regarding the agenda, focus of the tabletop, preparatory questions, and, if desired, the scenario. Out-of-town participants should also receive information on lodging, restaurants, transportation from the airport (including maps to the hotel and to the tabletop location if different), and responsibility for expenses. Information about the city (usually available from the local Chamber of Commerce or convention and visitor's bureau) may be included. The timing for sending invitations and supplementary information should be determined in advance by the planning committee and the dates included in the schedule.

Registration forms, registration desk: If registration is required, preregistration should be encouraged. Registration forms may be sent out with letters of invitation for a large tabletop. This provides information in a useable form for the participant list. The check-in or registration table should be open well before the time the tabletop is to start (the evening before, if out-of-towners are expected). If the tabletop is held at a hotel, the registration table should be close to the hotel registration desk the evening before and near the entrance to the room in which the tabletop will be conducted on the day of the tabletop for the convenience of the participants. Extra copies of information sent to the participants should be available at registration.

Certificates and mementoes: Certificates indicating the name, date, and location of the tabletop as well as the participant's name are often sent to participants following a major tabletop. These certificates are tangible evidence to others of their participation and are important to many State, local, and other participants. At times, inexpensive souvenir mugs, pins, or hats with the tabletop name and possibly the utility logo are given as mementos.

Access and badging, name tags and tents: If the tabletop is held in a controlled facility, access lists and badges may need to be prepared in advance so the participants have no problems in gaining entrance. In addition, readable name tags should be made and given to participants as they check in before the tabletop. Color-coded name tags are sometimes useful (e.g., red for players, blue for observers, green for support staff). Readable name tents with player's names and organizations should be placed on the tables before the tabletop. They serve as both identifiers and place cards.

Contracts for use of facilities: For a very large tabletop, contracts may be required to guarantee blocks of lodging rooms or meeting rooms. The organization making the arrangements follows its own procedures for negotiating contracts. 
Refreshments and lunch: Coffee, tea, soft drinks, and some type of fruit juice should be available during breaks. Cookies or sweet rolls and fruit are a welcome addition. Time can be saved, and interactions greatly enhanced, if lunch is catered either in the meeting room or in an adjacent room. If the tabletop or workshop lasts two days, an early evening social gettogether on the first day encourages interaction among the participants. A sponsor can usually be found to fund the food for such a function, and frequently there is a cash bar.

Set-up of meeting room: Arrangements should be made to have the meeting room set up in the desired configuration. Audio-visual equipment should be tested before the tabletop begins. Electric cords should be taped down, and extra bulbs should be available for projection equipment.

Support staff: Managing a tabletop requires workers in addition to the planners. Clerical help, staff for the registration desk, chair and table movers, technicians to set up audio-visual equipment, and catering services are all needed. Most of the staff requirements will surface when the logistics are identified. 


\subsection{Conduct Period Tasks}

\subsubsection{Task H - Provide Support Services to Participants}

\section{CHECKLIST OF TASK H ACTIVITIES}

Welcome participants.

Have tabletop support staff available for registration (see Task $G$, Section 2.1.7).

Have tabletop support staff available for making travel arrangements, reproduction of materials, delivering messages, etc. for participants.

Have refreshments available for breaks; make lunch arrangements.

Develop and distribute final list of participants.

Distribute mementoes.

\section{COMMENTS}

The effort involved in planning is evident and pays off during the conduct period.

Host responsibilities: Planning committee members may act as hosts, greeting participants as they arrive and answering questions.

Tabletop support staff responsibilities: Support staff should be both at the registration table and available to assist the participants with tabletop-related or other problems such as changing travel arrangements. The staff should compile a final list of attendees with name, organization, address, phone and fax numbers, and electronic mail addresses to be distributed at the close of the tabletop. They should also be available to take messages and post them on a message board, reproduce any materials that may be needed, collect comment forms, etc.

Mementoes: (See Task G, Section 2.1.7) 


\subsubsection{Task I - Conduct the Tabletop}

\section{CHECKLIST OF TASK I ACTIVITIES}

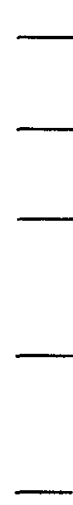

Introduce players.

Brief participants (developed in Task E, Section 2.1.5).

Introduce focus area(s), scenario; conduct tabletop discussion (developed in Task $D$, Section 2.1.4).

Ensure that back-up moderator provides feedback to moderator, recorders make appropriate notes.

Distribute participant comment forms (developed in Task F, Section 2.1.6).

\section{COMMENTS}

Player introductions: Players should give their name, organization, and the role they play in the response. They should not give an explanation of their responsibilities since this takes too much time. Formal presentations should be discouraged unless the tabletop is a multi-day affair. A few minutes per organization should be sufficient.

Moderator's responsibilities: At the beginning of the tabletop, players are briefed. The moderator should then set the stage by introducing the focus areas and scenario. $\mathrm{He} / \mathrm{she}$ should have a large store of questions that will encourage discussion. The back-up moderator is responsible for helping the moderator track the time and focus of the discussion. All players should be encouraged to volunteer information and ideas.

Recorders' notes: During the conduct of the tabletop, the recorders will make notes on questions, comments, and areas of agreement, and areas needing clarification or resolution. They may use special forms created for the purpose that will assist in structuring the final report. For example, the forms may track the focus areas and related questions with room under each question to jot down comments. Potential major lessons learned should be highlighted in some fashion when the note is taken. They may also send notes to the moderator, or backup moderator, or signal for follow-up questions. 


\subsection{Post-Tabletop Period Tasks}

\subsubsection{Task J - Determine Lessons Learned, Prepare Final Report, Follow-up \\ Conduct player debriefing immediately following tabletop. \\ Collect comment forms.}

Tabletop coordinator, moderator(s), recorders review tabletop (usually the following day).

Prepare lessons learned draft for review (format developed in Task $F$, Section 2.1.6).

Distribute final report within six months.

Follow up on response lessons learned.

Incorporate lessons learned on planning and conduct of tabletop in future tabletops.

\section{COMMENTS}

Players' debriefing: Immediately after the tabletop there is a brief break. The moderator then conducts a players' debriefing focusing on the major issues identified. Recorders take notes on the debriefing. Participants' comment forms should be collected before they leave the tabletop. Participants should be given a name, address, phone number, and fax number for use if they wish to send additional comments.

Development of the lessons learned report: Following the players' debriefing the tabletop coordinator, recorders and moderators(s) meet and reconstruct the comments of the tabletop using recorders' notes, players' debriefing, comment forms, and the moderators' input. This meeting is typically held the following day while key people are still at the tabletop location. The issues are identified and recommendations are made for improvement. Two aspects of the tabletop should be reported: (1) response lessons learned and (2) discussion of the planning and conduct of the tabletop. See Task F, Section 2.1.6, for contents of the lessons learned report.

The draft report should be ready for review within three months. Contractor support is helpful in compiling the report. In an interagency tabletop, representatives of the participating agencies are given an opportunity to comment on the draft report. The final report should be distributed within six months after the tabletop. A copy of the report is sent to each participant and others who may be interested (e.g., State and local organizations, utilities, and other Federal agencies). A copy is filed for future reference. 
Follow-up to lessons learned: Tabletop participants should take appropriate follow-up actions to address the issues raised (see Task F, Section 2.1.6, Final Report). Lessons learned on the planning and conduct of the tabletop are incorporated into future tabletops. A mechanism should be explored to determine follow-up activities. A one-year time period for tracking follow-up can be considered. Interagency working groups may be formed to resolve identified issues. 


\subsubsection{Task K - Complete Administrative Activities}

\section{CHECKLIST OF TASK K ACTIVITIES}

Complete any financial transactions.

Request that participants estimate time spent on tabletop, report to tabletop coordinator.

Compile file of information on tabletop for future reference and archives.

Write appropriate thank you letters; send certificates of participation.

\section{COMMENTS}

Tabletop file: This file will be compiled by the exercise coordinator from the information that was generated during the planning, conduct, and post-exercise periods. It will serve as an archival record and as reference material for future tabletops. It can include estimates of time needed for accomplishing different tabletop tasks.

Thank you letters, certificates: Thank you letters by the tabletop coordinator to the planners and staff involved, as well as to their supervisors, if they have done a good job, are appropriate. Thank you letters and certificates from the sponsoring organization(s) should be signed by the highest ranking official who participated in the tabletop. 


\subsection{SAMPLE TABLETOP}

\subsection{Use of Material}

The following scenario and associated questions can serve as a starting point for scenario development for tabletops. This example was developed as a comprehensive tabletop for top decision makers. It focuses on interagency coordination issues following a major nuclear power plant accident and covers the entire period of the response following the declaration of a site area emergency. This scenario would take a very long day or more to play. If planners are able to use the sample scenario to meet the goals and objectives of their tabletop, applicable parts of the scenario, data, and questions should be adapted to the local situation. Although radiological data are provided, in this tabletop (as in most), "number crunching" is not necessary. Although the events leading up to a site area emergency can be walked through in tabletop format, the later time periods in an emergency response, when coordination is required among many organizations, are most conducive to a tabletop discussion. The planners may choose to concentrate on one or more time periods. In the sample scenario and questions, blanks or parentheses [e.g., (utility), (State)] indicate places where specific identifiers should be inserted.

In this example, a moderator begins each time period or focus area with a brief description of current response activities. He or she focuses the discussion in each time period on areas of the interaction and coordination of the various response organizations. The moderator encourages players to identify the assistance needed by the State and local governments and the utility. As the focus areas are developed through further discussion of the scenario, consideration is given to who has what, who talks to whom, when, and the communications systems that will be used in the interactions. Rather than following the response in a completely sequential fashion, topics [such as request for deployment and activation of the Federal Radiological Monitoring and Assessment Center (FRMAC)] may be discussed as a unit, while noting other activities that may be taking place simultaneously. Each time period builds on the discussion from the previous time period. If participants need clarification or have disagreements, the moderator identifies the issue, recorders take note, and the discussion moves on rather than have participants try to solve the problem. 


\subsection{Time Period I}

Start: A Site Area Emergency has been declared.

End: All Federal response facilities, e.g., Joint Operations Center (JOC), Disaster Field Office (DFO), FRMAC, Joint Information Center (JIC) are operational.

\section{Visual Aids}

- Large map of the area close to the power plant (within about a 20-mile radius), with an overlay on which a recorder can write, showing the plant, 10-mile emergency planning zones, major cities, county names, airport, and major routes. The location of response facilities such as the FRMAC would be identified as they are discussed in the tabletop and highlighted on the map.

- Large map of extended area, with an overlay on which the recorder can write, showing the plant, the 10-mile and 50-mile emergency planning zones, major cities, county names, and major routes.

- Large sheets of paper on boards or easels for use if needed.

- Signs indicating scenario day and times. 
Scenario (Time Period I)

During the night, events occur at the (utility) Nuclear Power Plant which involve a substantial degradation of the safety of the plant.

0900 Unusual Event declared by (utility). (Utility) notifies State/Commonwealth, counties, and NRC. All respond according to their respective plans.

1000 Classification upgraded to Alert. Notifications are made; response according to plans. The status of the responding agencies is

(Utility): JIC activated, Technical Support Centers activated; monitoring teams at boundary; open phone line with NRC.

Counties: Emergency Operations Centers (EOCs) activated.

State: (State) EOC activated. (Support counties) notified; appropriate State agencies (insert names)-Liaisons sent to utility Emergency Operations Facility (EOF), state EOC; DOE/(name of region) Radiological Assistance Program (RAP) team alerted.

NRC: REGION (no.) -Regional Office Incident Response Center staffed; HQ staffed by standby teams;

(Utility): - NRC resident inspector at facility to assist in situation assessment.

FEMA: REGION (no.) -Regional Operations Center (ROC) activated and assessment of situation begun.

HQ-Monitoring situation and making internal and external notifications.

DOE: (Area Office) RAP team on alert.

\section{NOTE: Play begins at Site Area Emergency.}

1100 Site Area Emergency declared by (utility).

1130 Plant conditions: (Utility) has identified severe core damage; no release to the atmosphere is expected for at least 5 hours. When the release starts, it is expected to last 2 hours or more, with offsite doses exceeding 1 rem whole body and/or 5 rem infant thyroid.

Meteorological conditions: Wind from (direction), 4 miles per hour. There is heavy rain; rain should end by evening.

General Emergency declared by (utility). Notifications carried out. (State) Governor orders (appropriate sector) evacuation out to (appropriate number) miles.

1630 The release of radioactive materials to the environment starts. The plume is traveling from (direction) at 4 miles per hour. The projected dose out to a distance of about 4 miles will exceed Environmental Protection Agency (EPA) Protective Action Guides (PAGs). Evacuation is approximately (insert percentage) complete at the time the release starts. 


\subsubsection{Focus Area 1 and Principal Questions}

Identification, distribution, and management of resources to meet the needs of the State/local governments and general population.

1. What resources are the State/local governments expending?

2. What additional resources do the State/local governments anticipate needing?

3. Which Federal agencies can provide these resources?

4. What are the criteria for obtaining these Federal resources?

\subsubsection{Focus Area 2 and Principal Questions}

Activation and operational status of all emergency response facilities; the notification, interfaces among organizations, and coordination required for activation of these Federal facilities.

1. What centers will be activated to identify, distribute, and manage the resources to be supplied by the Federal government?

2. What are the criteria and processes by which each center is established, located, and activated?

3. What notifications and interfaces are required of the activated center?

4. What interfaces and coordination must occur both initially and continuously between and among the Federal, State, and other response facilities?

\subsubsection{Focus Area 3 and Principal Questions}

Interactions among the utility, State, local, and Federal responders related to the assessment of radiological data and protective actions based upon that assessment.

1. What interactions are required among responders to support the State's needs?

2. What are the initial assessment needs of the State related to plant status, consequence projections and field monitoring data, and protective action guidance?

3. What is the process for developing, presenting, and implementing Protective Action Recommendations (PARs)?

4. What interactions at each emergency response facility are required to address the State's needs? 


\subsubsection{Focus Area 4 and Principal Questions}

Provision of information to the public and the media.

1. What provisions have been made to address the media's need for up-to-date information?

2. What mechanisms are in place to respond to direct public inquiries?

\subsubsection{Related Preparatory Questions}

NOTE: Participating organizations should consider their response to appropriate questions in the following list to facilitate tabletop play.

1. What assistance could be requested from the NRC early in an event?
a. Which groups would be making requests?
b. Who in the organizations would be making those requests?
c. When and where would the NRC site team arrive?
d. To what other locations would NRC representatives go?
e. What radiological information and assessments would be initially available from the NRC?
f. Which Federal agencies make up the Advisory Team on Environment, Food, and Health?
g. What is the role of the Advisory Team on Environment, Food, and Health?
h. What information is available from the other Federal agencies?
i. How is that information obtained?

2. How can the State obtain an assessment of the potential consequences based on plant conditions?

3. What radiological assistance is available from DOE?
a. What are the criteria for determining whether DOE assistance is needed?
b. What are the mechanisms used by the State and DOE to coordinate radiological assistance?
c. What interactions would be expected between State emergency services organizations, State offices of radiation and environmental protection, DOE, and NRC regarding DOE radiological assistance and establishing a FRMAC?
d. What interaction would there be with local county officials regarding DOE activities?
e. Which positions in each organization would be interacting with other organizations?
f. Where would these people be located?
g. What radiological information and assessments would be available to the State and when?

4. How would DOE radiological assistance from the (DOE radiological assistance office) be coordinated with the State?

a. How long would it take advance RAP teams to arrive?

b. Where and to whom would they report? 
c. When would additional RAP teams be requested?

d. When and where would additional teams arrive and to whom would they report?

5. How are efforts of the State, utility, and Federal monitoring teams coordinated before a release?

6. When and where would the DOE Aerial Measuring System (AMS) arrive?

a. What arrangements would be made for its arrival and who would make them?

b. What arrangements would be made with the Federal Aviation Administration and by whom?

c. To whom do the AMS personnel report? Where?

7. After the release starts, how is field monitoring coordinated offsite?

a. Who is responsible for coordinating the effort and at what point does it change?

8. How is a FRMAC set up?

a. Who decides on a FRMAC location?

b. How is the space procured and by whom?

c. How are affected parties (county, other agencies) notified of the FRMAC location and by whom?

d. When would the FRMAC become operational?

9. Where will DOE coordinate requests for assistance that are not part of the mission for FRMAC?

10. What actions, if any, would FEMA headquarters and regional offices take:

a. Site Area Emergency?

b. At General Emergency?

c. In response to a decision by NRC to enter either a standby or activation (initial or expanded) operational response mode?

11. What is the role of the FEMA ROC in a radiological emergency?

a. Who decides to activate the ROC and when?

b. Would representatives from Emergency Support Function (ESF) Primary Agencies participate in ROC operations in a radiological emergency? If so, which ESFs would participate?

c. What is the relationship between the ROC and the DFO?

12. What is the role of the interagency Emergency Support Team (EST) in a radiological emergency?

a. When and how would the EST be activated?

b. Which Federal agencies would send representatives to the EST in a radiological emergency and when?

c. What is the role of the EST representatives from each ESF Primary Agency during a radiological emergency?

d. What is the relationship between operations in the EST and those in the NRC Operations Center?

e. How would the level of EST operations change over time during the response?

13. At a General Emergency (or sooner), what help, if any, would the (State) request from FEMA?

a. Which groups would make requests? From whom?

b. How does the (State) communicate such requests?

c. What requests would the (State) communicate directly to the Lead Federal Agency (LFA)? 
d. What requests would the (State) communicate directly to other Federal agencies?

14. After a serious accident at a commercial nuclear power station, when would the (State) request a Presidential declaration of major disaster or emergency?

a. What types of unmet needs does the (State) expect in such a scenario?

b. What type of declaration would the (State) request and why?

c. With what other organizations does FEMA interact when processing a request for a Presidential declaration?

d. Can a radiological emergency be a major disaster under the Stafford Act?

15. What is the role of the Advance Element of the Emergency Response Team (ERT-A) in a radiological emergency?

a. What is the relationship between the Senior FEMA Official (SFO) and the ERT-A Team Leader?

b. When and where does the ERT-A arrive?

c. What is the relationship between the ERT-A and the full ERT?

d. When does the full ERT arrive?

16. What is the relationship between the SFO and the Federal Coordinating Officer (FCO)?

a. When does the SFO deploy and to where?

b. What is the relationship between the SFO and the LFA Official or Federal On-scene Commander (OSC), in this case, the NRC Director of Site Operations?

c. Who will be the FCO and what will be the relationship between the FCO and the Federal OSC?

d. Where and how does that interaction occur?

e. What is the relationship among the FCO, OSC, and State Coordinating Officer (SCO)?

17. What is the role of the Catastrophic Disaster Response Group (CDRG) in a radiological emergency?

a. Who convenes the CDRG in a radiological emergency, and when? Where is the CDRG located?

b. Can the CDRG be convened before a State requests a Presidential declaration of major disaster or emergency?

18. What process does FEMA use to determine whether to establish a DFO at the scene of a radiological emergency?

a. Where is the DFO located?

b. Who sets it up?

c. Which agencies are invited to participate in the DFO and when are they invited?

d. What roles do representatives from ESF Primary Agencies serve in the DFO?

e. What is the status of the ROC after the DFO is operational?

f. What interaction would there be between county and municipal officials and the DFO?

19. How does the DFO get radiological information with which to assess the extent of the damage (perform a preliminary damage assessment)?

a. What function does the DFO representative in the FRMAC serve?

b. What function does the FRMAC representative in the DFO serve?

20. What support do EPA, HHS, and USDA provide the State, counties, and other Federal agencies? 
a. Where can the State obtain assistance in applying the protective action guidance of EPA, HHS, and USDA? What is the role of the Advisory Team for Environment, Food, and Health?

b. What, if any, coordination is required for additional protective actions (e.g., animals on stored feed, closure of waterways, guidance on drinking water)?

21. What role does ESF 5 (Information and Planning - FEMA) have in a radiological emergency?

a. Does ESF 5 use radiological data and if so, for what?

b. Who in the DFO prepares situation reports and what does the DFO do with these reports?

c. What information does ESF 5 report and to whom?

d. What are the sources of information for ESF 5?

22. What mechanisms are in place to provide financial assistance to the public during these initial phases of response?

23. What information is being provided to the public and the media?

a. From what sources and location(s) will public information be coming and with what frequency?

b. What changes in location of media operations occur during this time period? Who goes where? What are the criteria for the change?

24. What information will need to be provided to the Congress and the White House?

a. Whose responsibility will it be to provide information to the Congress and the White House and from where will it come? 


\subsection{Time Period II}

Start: All Federal response facilities (e.g., JOC, DFO, FRMAC, JIC) are operational.

End: The plant is stable, no more releases are expected, and radiation impact to the environment is characterized.

\section{Visual Aids}

- A map overlay that shows preliminary projected 1-year radiation doses due to accident (Appendix D).

Scenario (Time Period II)

The time is about 24 hours after the declaration of the General Emergency. The 2-hour release stopped the preceding day. The plant is coming under control. The General Emergency classification is still in place. The weather is clearing with a 4 miles per hour wind from the (direction).

Evacuation of (appropriate sectors) in the 10-mile Emergency Planning Zone (EPZ) is complete except for those persons (e.g., some very ill persons in nursing homes, other institutions) who could not be evacuated. Approximately 40 percent of the over (insert number) evacuees are in county shelters operated by the American Red Cross; the remaining persons are with relatives and friends. Out-of-town relatives of evacuees are concerned about their welfare. The evacuees are becoming concerned about getting their mail, doing their banking, the safety of their property in the evacuated area, and getting necessary supplies such as medicines. The (name of water way) has been closed to boaters, and airspace over the area is restricted.

Potassium iodide has been issued to emergency workers and institutionalized persons who could not be evacuated before the plume passed. Farmers want to return to the evacuated area to care for their livestock.

The JOC, located in the EOF, and JIC are operating with the Federal and State personnel and liaisons present. The near-site Federal response facilities (DFO and FRMAC) are activated in (location) and (location). The State Coordinating Office and DFO are (colocated or not co-located). State personnel are at the FRMAC. All Federal personnel and resources, including additional monitoring teams, mobile laboratories from EPA and NRC, and the FEMA communications capabilities, are in place. The major FRMAC monitoring resources are one aircraft and 15 Federal field teams per shift.

AMS preliminary plots (wide spacing) are available to FRMAC, State, and NRC. The DOE Atmospheric Release Advisory Capability (ARAC) predictions, as well as State, NRC, and utility plots are updated. RAP, State, and utility off-site data (including early food, water, soil, and commercial product contamination data) are available to the FRMAC, State, and NRC.

The Catastrophic Disaster Response Group is meeting in Washington, D.C.

The Advisory Team for Environment, Food, and Health is in transit to the site; will co-locate with the FRMAC.

Communication links among the facilities are in place. 


\subsubsection{Focus Area 1 and Principal Questions}

Identification, distribution, and management of resources to meet the needs of the population, including a Presidential declaration under the Stafford Act and utilization of the Price Anderson Act (for questions of financial responsibility and reimbursement).

1. What additional resources are required to meet the ongoing needs of the State and general population?

2. What information would be required by the Federal government from the State for a Stafford Act declaration?

3. What are the processes for using the Stafford Act, Price Anderson Act, and other mechanisms for supplying financial assistance?

4. What mechanisms are in place to address financial concerns for long-term public and environmental problems?

\subsubsection{Focus Area 2 and Principal Questions}

Interactions among the utility, State, local, and Federal responders, including consideration of the needs of the counties and the assessment of radiological data related to ingestion and intermediate phase guidance.

1. What are the necessary interfaces among the responders to determine appropriate ingestion pathway and intermediate phase issues for Federal assistance?

2. What priorities should be established for the assessment of radiological data and associated protective actions?

3. What are the longer-term needs of the State and local response organizations for vereruning health and environmental effects?

\subsubsection{Focus Area 3 and Principal Questions}

Provision of information to the public through rumor control and the media.

1. How will questions from the public be handled?

2. What information needs can be anticipated for the media, the White House, and Congress?

3. What centers need to be maintained for interactions among State and Federal public affairs personnel and the media? 


\subsubsection{Related Preparatory Questions}

NOTE: Participating organizations should prepare answers to the appropriate questions in the following list to facilitate meaningful tabletop play.

1. What resources and services are needed to meet the needs of the affected/evacuated population?

2. What does the (State) consider in requesting a Stafford Act declaration?
a. What criteria does FEMA use in evaluating the (State) request (i.e., what information is required to substantiate the severity and magnitude of this incident to justify a Stafford Act declaration)?
b. Depending on the (State) unmet needs, what types of Federal assistance are available with a Stafford Act declaration?

1) What are the prerequisites for obtaining that assistance?
c. How do the Federal and State governments work together for a Presidential declaration under the Stafford Act?

3. What are the differences in assistance available under an emergency versus a major disaster declaration?
a. What impact will a Presidential declaration of major disaster or emergency have on the ongoing Federal/State response?
b. How does the Federal/State response change after a major disaster or emergency declaration under the Stafford Act?
c. What happens if the President decides not to declare a major disaster or emergency?
d. What happens if the President independently declares a major disaster or emergency?

4. How do Federal and State governments work together under the ESF concept to address response requirements?

5. What are the roles and responsibilities of local, State, and Federal agencies in the prevention of exposure to, and the mitigation of impacts on, the human and animal food chain?
a. What assistance will be required and who will manage the acquisition of environmental samples and laboratory analysis of materials collected?

6. What is the process for developing and presenting PARs to the (State)?
a. What is the role of the Advisory Team for Environment, Food, and Health?
b. What is the role of NRC?
c. What is the role of FEMA?
d. Where do these interactions occur?

7. What are the resources of the Federal government and State to assess the level of contamination and whether or not the intermediate phase PAGs apply?

8. Who will formulate and disseminate ingestion pathway PARs?
a. What data and standards will be used?
b. How will the recommendations be coordinated among the agencies?
c. How will differences be resolved?

9. What is the role of the CDRG in this phase of the response after all onscene Federal operations centers are fully operational? 
a. Are all appropriate agencies to address operational response needs represented on the CDRG?

10. How does the DSO provide FEMA with radiological information needed for ongoing situation assessments?

a. Can FEMA obtain this information directly from its liaison in the FRMAC, or is there another interface structure for this purpose?

11. What is the scope and coverage of American Nuclear Insurers and Mutual Atomic Energy Liability Underwriters (ANI/MAELU) funding of onscene response operations?

a. Describe the structure and process by which ANI/MAELU will distribute funds, as well as provide services (such as temporary housing and mass care), during this phase of the response.

b. What is the relationship between ANI/MAELU funds and funds available through the Stafford Act?

c. What is the relationship between ANI/MAELU Claims Centers and the DFO?

d. What types of information will ANI/MAELU Claims Centers and the DFO need from each other?

e. Can ANI/MAELU funds be used to compensate the State and local groups for response-related expenses?

12. Who will determine when reentry into the contaminated areas in order to perform essential functions will be allowed?

a. Who will be permitted to enter?

b. What exposure control methods will be used?

c. Who will announce reentry procedures to the public?

13. What information is being provided to Congress and the White House?

a. By whom?

b. From what locations?

14. What information is being provided to the public and media during this phase of the response?

a. By what organizations?

b. What are the main locations from which information will be released? 


\subsection{Time Period III}

Start: Plant is stable, no more releases are expected, and radiation impact to the environment has been characterized.

End: Requirements and organizations for long-term oversight are established.

\section{Visual Aids}

- A map overlay which shows projected 1-year doses from the accident within the 10-mile EPZ at levels which would not allow the population to return and areas in the ingestion pathway which would require embargoes of some agricultural products (Appendix D).

\section{Scenario (Time Period III)}

This period starts approximately 5 days after the release has been terminated. The weather has been clear. The ground deposition is well-defined. The reactor shutdown is complete; no onsite condition will impact offsite recovery.

The population is still evacuated out to 10 miles; evacuees are anxious to know who can return to their homes and when. Farmers and food producers want information on the longterm effects on their land and crops. The tourist industry in the area has declined precipitously. Owners of wells are concerned about use of the water.

All near-site response centers are functioning. In the FRMAC, the EPA is assuming leadership.

The Federal and State monitoring efforts have strained the mobile and fixed laboratory resources. Priorities have been set for analyses. Detailed AMS plots, ground-based measurements, and contours for relocation PAG levels, food, and milk have been developed. The contamination is well-defined; AMS and field data are integrated to produce final concentration and exposure rate contours. Most of the area is not contaminated. Population reentry decisions are being made. Some areas close to the plant in the plume pathway are too heavily contaminated for the return of the population. Farther out in the 10-mile EPZ, some decontamination is necessary before return of evacuees. Food and milk embargoes have been established for portions of the 10-mile and 50-mile EPZs. 


\subsubsection{Focus Area 1 and Principal Questions}

Identification, distribution, and management of resources to meet the long-term needs of the State and general population.

1. What are the long-term recovery issues and what resources are needed to address them?

2. How will resources for the long term be managed by the State and Federal government?

3. What organizations and mechanisms will be established to identify and provide resources?

\subsubsection{Focus Area 2 and Principal Questions}

Organizations created and considerations in addressing the recovery questions.

1. How will priorities be established for recovery issues?

2. What organizations will be established to address recovery issues?

3. What local, State, and Federal (regional and national level) organizations will have a major role in determining priorities for recovery?

4. What major decisions are required by local and State responders to assure that all necessary precautions have been taken regarding food and health?

5. What mechanisms will be established for assuring that the environment in the affected area will be recovered or fenced off?

\subsubsection{Related Preparatory Questions}

NOTE: Participating organizations should prepare answers to appropriate questions in the following list to facilitate meaningful tabletop play.

1. What is the role of the CDRG in this phase of the response?

a. Are all appropriate agencies represented on the CDRG to address long-term recovery needs?

b. Who is the Defense Coordinating Officer (DCO) and what is the role of the DCO in this type of scenario?

2. What is the role of the Federal Advisory Team on Environment, Food, and Health in this phase of the response?

3. How will the boundaries of areas requiring access control, quarantines, and embargoes be determined?

a. Who determines when the people can return to evacuated areas?

b. What standards will be used and what coordination will be needed before residents are allowed to return?

c. Who determines which residents of marginally contaminated areas not evacuated during the emergency phase of operations should now be relocated to prevent acquisition of unacceptable long-term doses? 
d. Who determines appropriate methods of protection for individuals remaining in areas of low-level contamination?

4. What support is available for the residents who are not allowed to return to the evacuated area for significant amounts of time?

5. What support is available to evaluate health risks and maintain health surveillance, provide logistics for long-term shelter operations, provide psychological counseling services, and disseminate appropriate information to the public in the area?

6. Who is responsible for development and implementation of the long-term environmental monitoring and recovery plan?

a. What support can be called upon?

b. What is the approval process for this plan?

7. What is the basis for selection of criteria and the establishment of guidelines for recovery of contaminated areas, for area restoration, and for certification of the completion of decontamination/area restoration activities?

a. Who is responsible for decontamination and area restoration costs, including the recovery of contaminated property and equipment?

b. Who is responsible for damage assessment and determination of short- and longterm economic impacts?

8. Who bears the responsibility and what is the process for the reimbursement of recovery expenditures and the replacement of individual losses resulting from the event?

9. Who determines the required actions and procedures for prevention of the spread of deposited contamination from the restricted zone, removal of contaminated soils or other materials, and disposal of contaminated waste and debris?

a. How and by whom is the location of monitoring and decontamination stations in support of restricted zones determined?

b. Who establishes action levels or limits of contamination for personnel and equipment leaving the restricted zone?

10. What information is being provided to Congress and the White House during this phase of the response?

a. By whom?

b. From what locations?

11. What process will be used to keep the public and media informed of long-term recovery developments?

12. How, when, and under what criteria would Federal agencies deactivate their emergency response activities?

a. What coordination would be required before making the decision to deactivate?

b. Who makes the decision to deactivate State and Federal response activities?

13. What continuing (long-term) Federal assistance would be available to the State and counties following deactivation of a Federal response? 
APPENDIX A

ACRONYMS AND INITIALISMS 


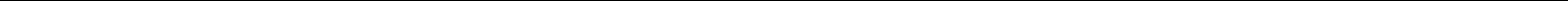


AMS

ANI/MAELU

ARAC

CDRG

DCO

DFO

DOE

DOD

DOI

EOC

EOF

EPA

EPZ

ERT

ERT-A

ESF

EST

FCO

FEMA

FFE

FRERP
Aerial Measuring System

American Nuclear Insurers/Mutual Atomic Energy Liability Underwriters

Atmospheric Release Advisory Capability

Catastrophic Disaster Response Group (Federal interagency group)

Defense Coordinating Officer

Disaster Field Office (FEMA coordinates)

U.S. Department of Energy

U.S. Department of Defense

U.S. Department of the Interior

Emergency Operations Center

Emergency Operations Facility

U.S. Environmental Protection Agency

Emergency Planning Zone

Emergency Response Team (Federal interagency team)

Advance Element of the Emergency Response Team (Federal interagency team)

Emergency Support Function (Federal Response Plan)

Emergency Support Team (Federal interagency team)

Federal Coordinating Officer

Federal Emergency Management Agency

Federal Field Exercise

Federal Radiological Emergency Response Plan 
FRMAC

FRP

HHS

HQ

JIC

JOC

LFA

NRC

OSC

PAG

PAR

RAP

ROC

$\mathrm{SCO}$

SFO

TTPLAN

USDA
Federal Radiological Monitoring and Assessment Center (DOE, then EPA coordinates)

Federal Response Plan

U.S. Department of Health and Human Services

Headquarters

Joint Information Center

Joint Operations Center (Lead Federal Agency coordinates)

Lead Federal Agency

U.S. Nuclear Regulatory Commission

Onscene Commander (Federal)

Protective Action Guides

Protective Action Recommendation

Radiological Assistance Program (DOE)

Regional Operations Center (FEMA)

State Coordinating Officer

Senior FEMA Official

Tabletop Plan

U.S. Department of Agriculture 
APPENDIX B

LIST OF PUBLICATIONS THAT MAY BE USED

AS REFERENCES 

The following publications may be useful as reference material for planning and to distribute to participants in a large interagency tabletop dealing with a power reactor accident. This list may be augmented with other agency-specific plans and procedures. Planners of tabletops on other topics should develop similar reference lists.

Atomic Energy Act of 1954, as amended, 42 U.S.C.

Federal Emergency Management Agency, "Federal Radiological Emergency Response Plan," Federal Register, Vol. 59, No. 171, Sept. 6, 1994, pp. 46086-46107.

_- Federal Response Plan for Public Law 93-288, as amended, FEMA 229, April 1992.

U.S. Department of Energy, FRMAC-93 Lessons Learned Report, DOE/NV-367, Las Vegas, Nevada, March 1994.

- - Federal Radiological Monitoring and Assessment Center (FRMAC) Overview of FRMAC Operations, DOE/NV 358, Rev.2, FRMAC-10-94, Las Vegas, Nevada, July 1994.

U.S. Nuclear Regulatory Commission, NUREG-0728, "NRC Incident Response Plan," Rev. 2, June 1987.

- - NUREG-0845, "Agency Procedures for the NRC Incident Response Plan," Final Report and Supplements, February 1983.

- - NUREG-1467, "Federal Guide for a Radiological Response: Supporting the Nuclear Regulatory Commission During the Initial Hours of a Serious Accident," November 1993.

- - NUREG-1442, "Emergency Response Resources Guide for Nuclear Power Plant Emergencies," Rev. 1, July 1992.

- - NUREG-1457, "Resources Available for Nuclear Power Plant Emergencies Under the Price-Anderson Act and the Robert T. Stafford Disaster Relief and Emergency Assistance Act," July 1992.

- - NUREG-1471, "Concept of Operations With Organization Charts: NRC Incident Response," February 1994.

_- NUREG/BR-0150, "The Response Technical Manual," Vol. 1, Rev. 3, November 1993.

- - and Federal Emergency Management Agency, NUREG-1441 (FEMA-REP-16), Lessons Learned From the Post-Emergency TABLETOP Exercise in Baton Rouge, Louisiana, on August 28 and September 18, 1990. 


\section{APPENDIX C \\ TABLES OF CONTENTS FROM \\ TWO LESSONS LEARNED REPORTS}


Table of Contents from Lessons Learned From the Post-Emergency TABLETOP Exercise in Baton Rouge, Louisiana, on August 28 and September 18, 1990

Table of Contents

Page

Abstract $\ldots \ldots \ldots \ldots \ldots \ldots \ldots \ldots \ldots \ldots \ldots \ldots \ldots \ldots \ldots \ldots \ldots \ldots \ldots \ldots$ iii

Foreword $\ldots \ldots \ldots \ldots \ldots \ldots \ldots \ldots \ldots \ldots \ldots \ldots \ldots \ldots \ldots \ldots \ldots \ldots$ vii

Executive Summary $\ldots \ldots \ldots \ldots \ldots \ldots \ldots \ldots \ldots \ldots \ldots \ldots \ldots \ldots \ldots$

Introduction $\ldots \ldots \ldots \ldots \ldots \ldots \ldots \ldots \ldots \ldots \ldots \ldots \ldots \ldots \ldots \ldots \ldots \ldots$

Background $\ldots \ldots \ldots \ldots \ldots \ldots \ldots \ldots \ldots \ldots \ldots \ldots \ldots \ldots \ldots \ldots \ldots$

Purpose $\ldots \ldots \ldots \ldots \ldots \ldots \ldots \ldots \ldots \ldots \ldots \ldots \ldots \ldots \ldots \ldots \ldots \ldots$

Organization $\ldots \ldots \ldots \ldots \ldots \ldots \ldots \ldots \ldots \ldots \ldots \ldots \ldots \ldots \ldots \ldots \ldots$

Acknowledgements $\ldots \ldots \ldots \ldots \ldots \ldots \ldots \ldots \ldots \ldots \ldots \ldots \ldots \ldots \ldots \ldots \ldots$

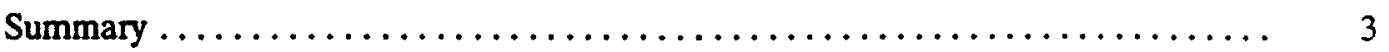

Summary of TABLETOP Activities $\ldots \ldots \ldots \ldots \ldots \ldots \ldots \ldots \ldots \ldots$

Summary of Major Lessons Learned $\ldots \ldots \ldots \ldots \ldots \ldots \ldots \ldots \ldots \ldots$

Development of the TABLETOP $\ldots \ldots \ldots \ldots \ldots \ldots \ldots \ldots \ldots \ldots \ldots \ldots$

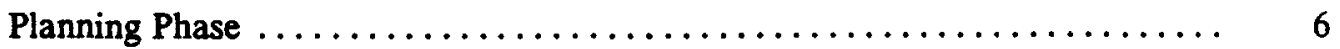

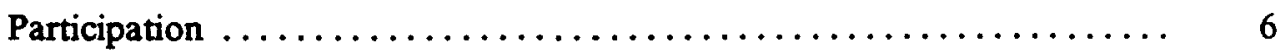

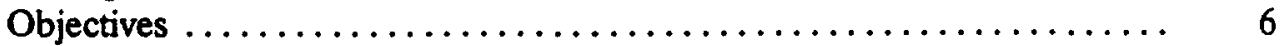

Documentation $\ldots \ldots \ldots \ldots \ldots \ldots \ldots \ldots \ldots \ldots \ldots \ldots \ldots \ldots \ldots \ldots \ldots$

Conduct of the TABLETOP $\ldots \ldots \ldots \ldots \ldots \ldots \ldots \ldots \ldots \ldots \ldots \ldots$

Post-TABLETOP Phase $\ldots \ldots \ldots \ldots \ldots \ldots \ldots \ldots \ldots \ldots \ldots \ldots$

Work Products $\ldots \ldots \ldots \ldots \ldots \ldots \ldots \ldots \ldots \ldots \ldots \ldots \ldots \ldots \ldots$

Discussion $\ldots \ldots \ldots \ldots \ldots \ldots \ldots \ldots \ldots \ldots \ldots \ldots \ldots \ldots \ldots \ldots \ldots \ldots \ldots \ldots \ldots$

August 28, 1990 Session-Federal, State, Parish, and Utility Response

Capabilities ................................. 8

September 18, 1990 Session-Federal Assistance to State and Local Agencies . 10

Focus Area A: Ingestion Pathway Response . . . . . . . . . . . . 10

Focus Area B: Reentry, Relocation, and Return . . . . . . . . . . . 14

Focus Area $\mathrm{C}$ : Decontamination and Recovery $\ldots \ldots \ldots \ldots \ldots \ldots \ldots$

Focus Area D: Indemnification of Financial Losses . . . . . . . . . . 18

Focus Area E: Deactivation of the Emergency Response . . . . . . . . . 21

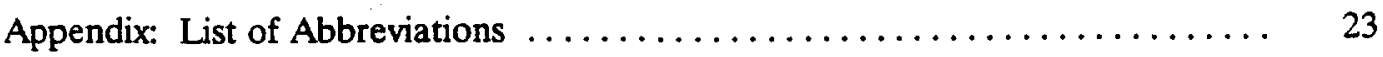


Table of Contents from Kewaunee Nuclear Power Plant Regulatory Exercise September 24-26, 1991: Report on Participation by Federal Agencies as Players

Table of Contents

I. Introduction $\ldots \ldots \ldots \ldots \ldots \ldots \ldots \ldots \ldots \ldots \ldots \ldots \ldots \ldots \ldots$
A. Background
B. Purpose of Federal Participation
C. Exercise Scenario Overview

II. Concept of Operations for Federal Participantion
A. Scope of Federal Participation
B. Definition of the Federal Response Cell
C. Location of Response Cell
D. Interfaces Between States and Federal Participants

III. Lessons Learned $\ldots \ldots \ldots \ldots \ldots \ldots \ldots$. . . . . . . . . . . . .
A. Objectives for Federal Participation
B. Design of the Exercise
C. State and Local Government Familiarity with Federal
Response Roles . . . . . . . . . . . . . . . III-I
D. Summary $\ldots \ldots \ldots \ldots \ldots \ldots \ldots \ldots \ldots \ldots \ldots \ldots \ldots$

Appendix A - Nuclear Regulatory Commiscion - Kewaunee Federal Response Cell Obeervations and Lessons Learned . . . . . A-1

Appendix B - Break Messages . . . . . . . . . . . B-1

Figure 1 - Kewaunee Nuclear Power Plant Exercise Time Line . . . I-4 
APPENDIX D

RADIOLOGICAL INFORMATION FOR SAMPLE SCENARIO 


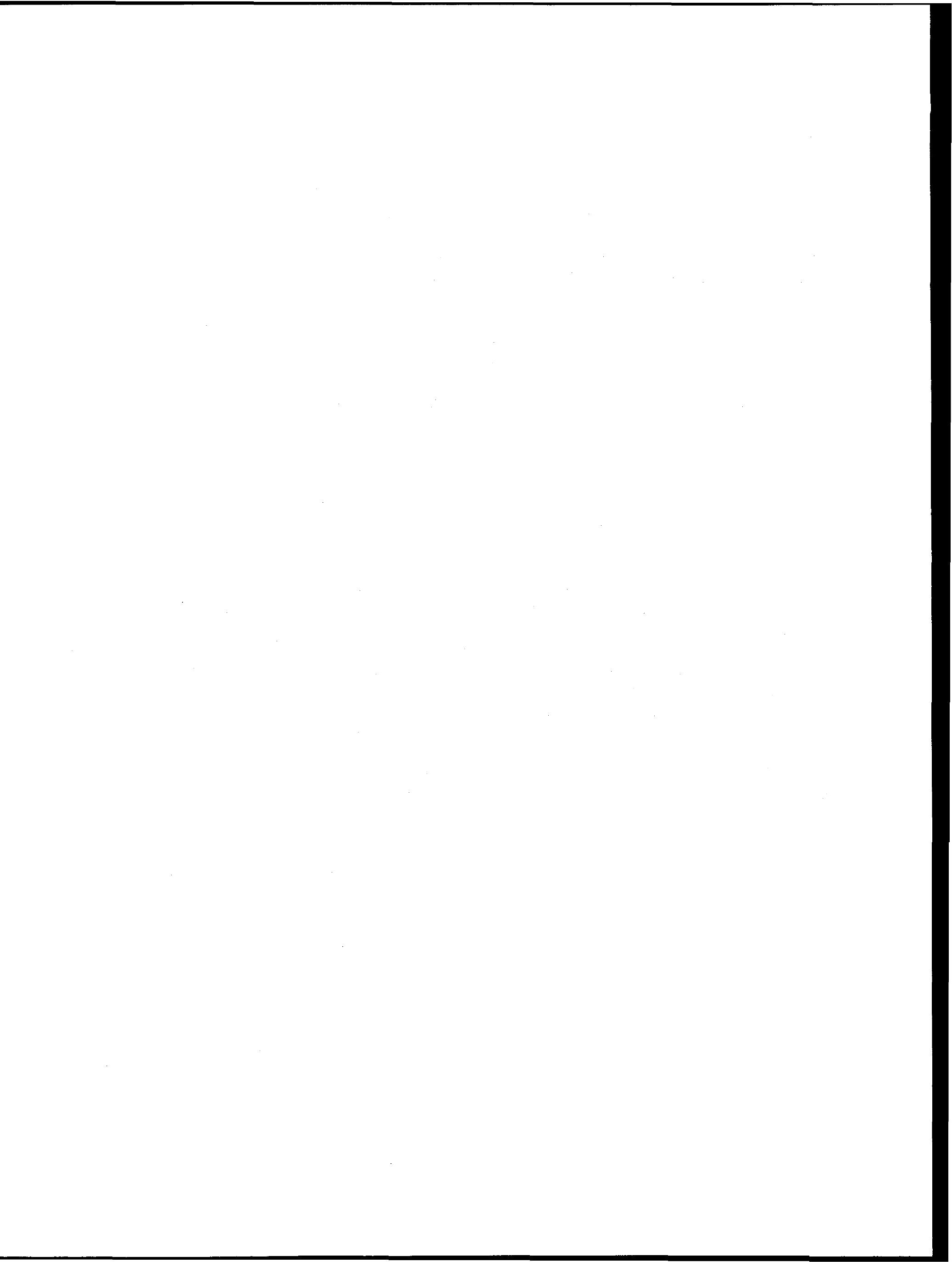


The radiological information presented here is an example. It is not very detailed and does not accurately represent the available information at all times in the scenario. It must be adapted to local conditions. The information is included only to help prompt discussion of the types of decisions that must be made and the process by which those decisions are made, not to initiate a technical discussion.

This radiological scenario assumes severe core damage at the reactor, with the core uncovered for more than 30 minutes. About $1 / 24$ of the available material is released over 2 hours. There is a steady 4-mph wind, going from south to north, up the river valley. There is heavy rain at the time of the release. The rain ends by evening, and the weather remains clear though the next 5 days.

During Time Period I, the first available information may be a projection based on plant conditions and current weather. (Protective action decisions will probably be made based on the conditions at the plant.) The dose projections will become better defined as more information becomes available and monitoring data come in. Some field data will be available by the end of Time Period $I$.

Maps with limited radiological data will be available by the beginning of Time Period II. Figure D.1 shows the dose projection based on initial aerial and ground monitoring. These projections will be refined as more data become available and the areas enclosed by the contours will shrink. Contours include 2 rem ( $2000 \mathrm{mrem})$ projected in the first year (EPA relocation PAG), $500 \mathrm{mrem}$ in the first year [boundary of (state) restricted zone], and 100 mrem in first year [outer boundary of (state) study zone]. A separate contour indicates the boundary of area possibly contaminated to a degree that milk and some produce from the area might exceed ingestion PAGs.

By the beginning of Time Period III, the radiological situation should be much clearer. Figure D.2 shows smaller and more irregular contour lines for the different dose levels described earlier. A contour showing the area where the plume exposure would have exceeded the EPA 1 rem whole body PAG is also shown.

Table D.1 provides isotopic fractions in the ground deposition for different times for those who want information on the isotopic mix used in this scenario. 


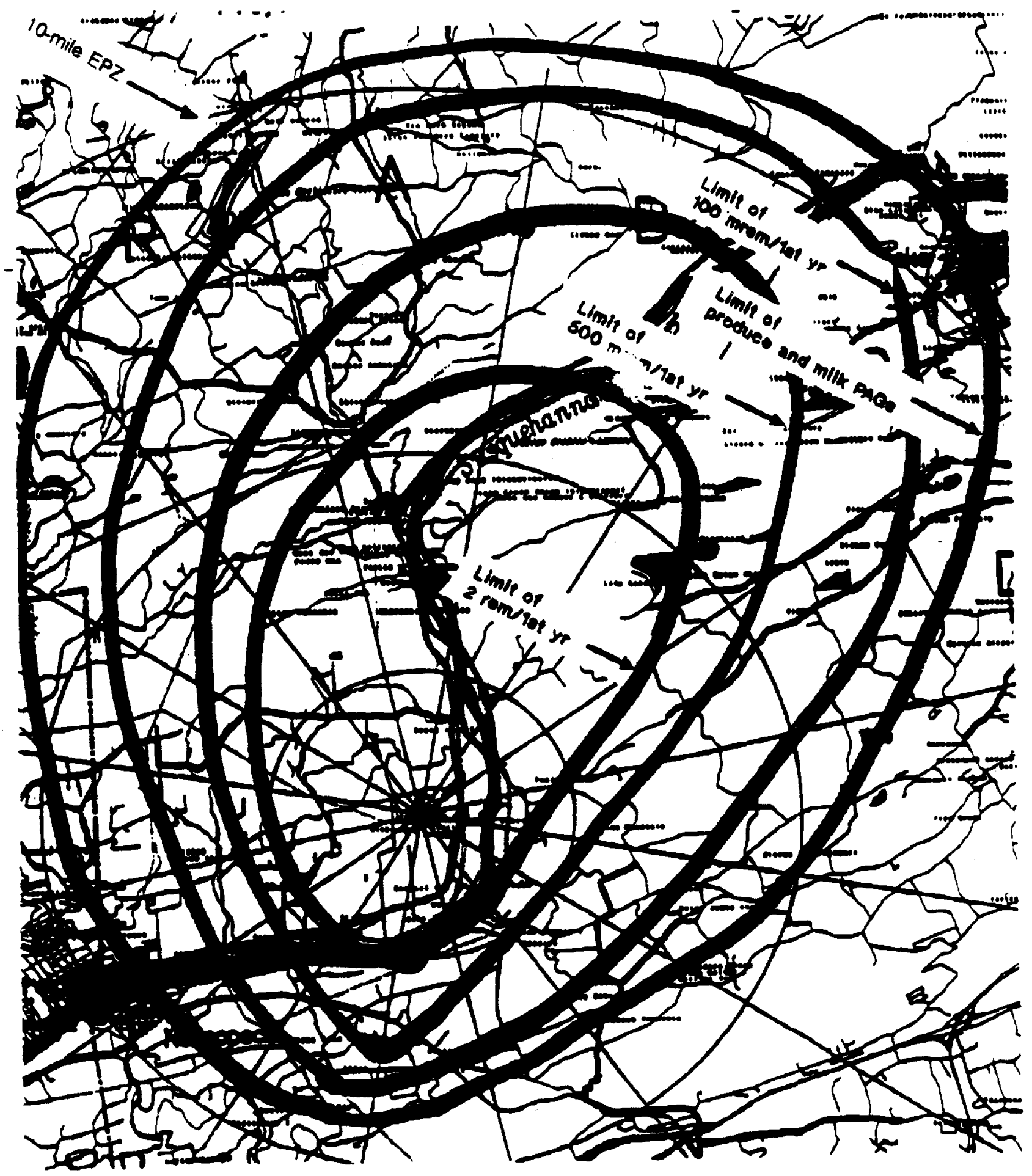

Fig. D.1. Isodose contours based on initial aerial and ground monitoring, available at beginning of Time Period II. 


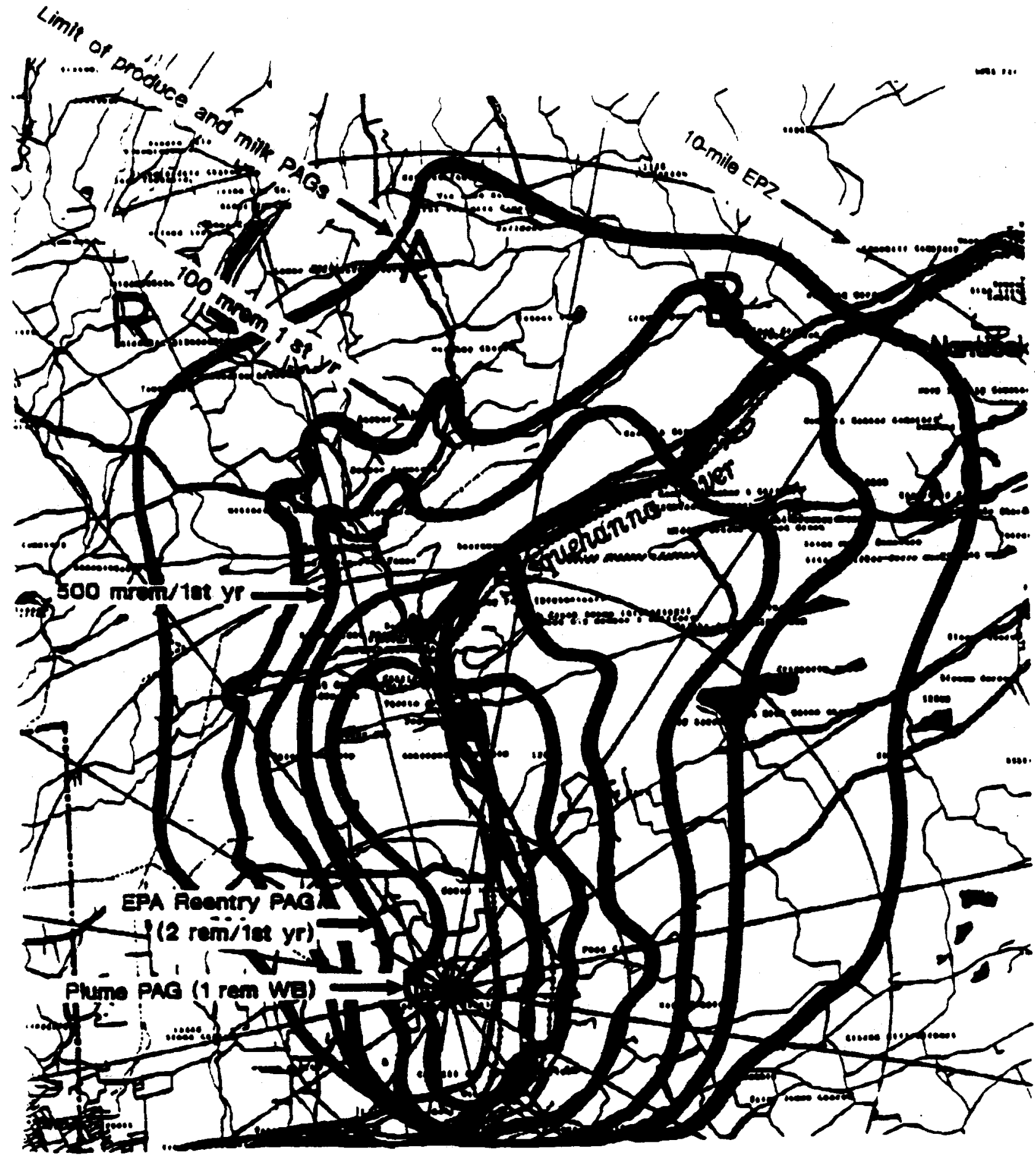

Fig. D.2. Refined isodose contours based on extensive monitoring, available at the beginning of Time Period III. 
Table D.1. Isotopic Fractions for Ground Deposition by Time After Reactor Shutdown

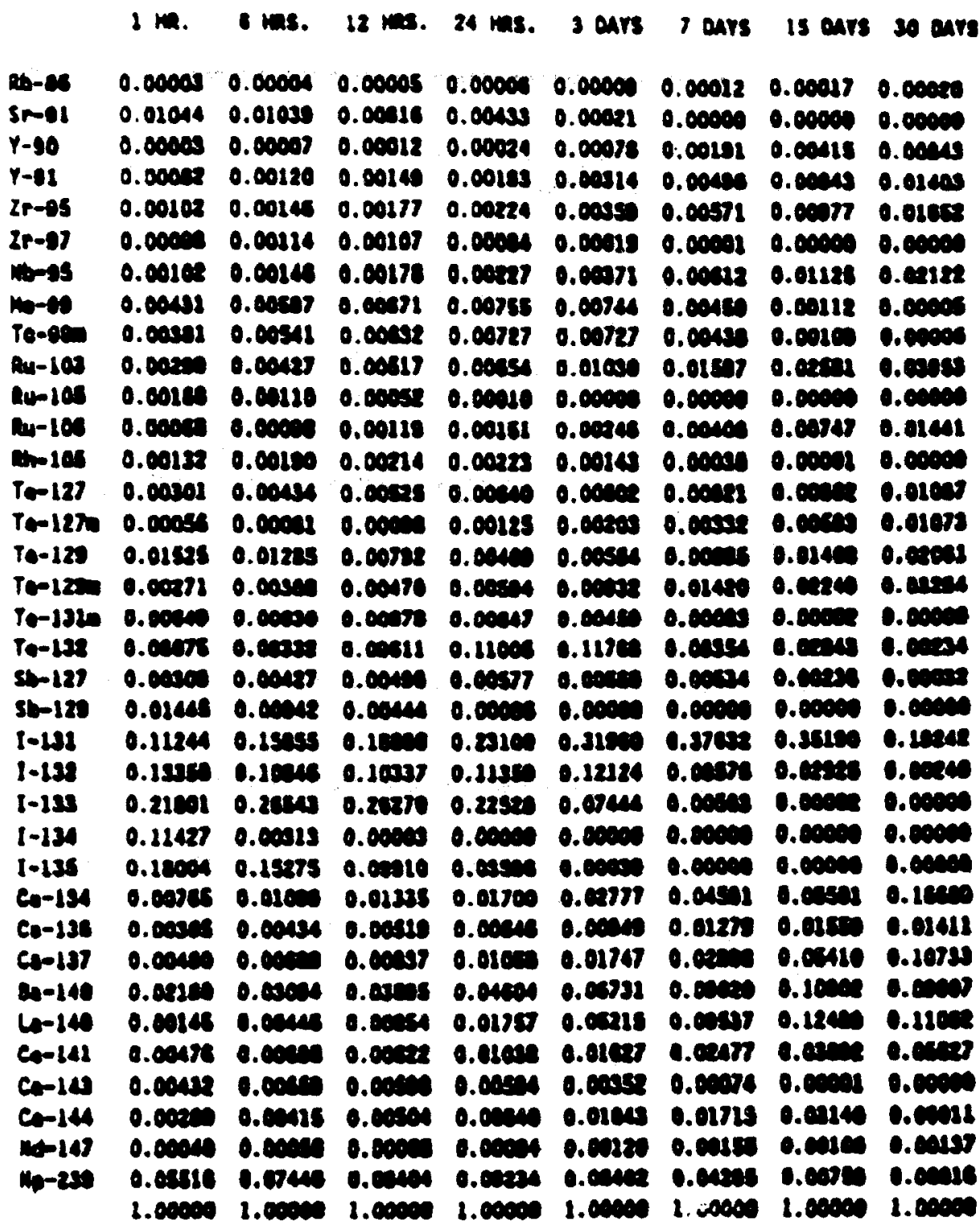


BIBLIOGRAPHIC DATA SHEET

(See instructions on the reverse)

\section{TITLE AND SUBTITLE}

Guidance for a Large Tabletop Exercise for a Nuclear Power Plant

5. AUTHOR(S)

E. D. Weinstein, E. F. Bates/U.S. Nuclear Regulatory Commission

M. V. Adler, K. S. Gant/Oak Ridge National Laboratory
1. REPORT NUMBER

(Assigned by NAC, Add Vol.

Supp., Rev., and Addendurn 'Num-

bers, if any, )

\section{NUREG-1514}

3. DATE REPORT PUBLISHED

\begin{tabular}{l|r} 
MONTH & YEAR \\
March & 1995
\end{tabular}

March

1995

4. FIN OR GRANT NUMBER

8. PERFORMING ORGANIZATION - NAME AND ADDRESS (If NRC, provide Division, Office or Region, U.S. Nuclear Regulatory Commission, and mailing address; if contractor, provide name and malling address.)

Office for Analysis and Evaluation of Operational Data

Oak Ridge National Laboratory

U.S. Nuclear Regulatory Commission

Oak Ridge, TN 37831-6285

Washington, D.C. 20555-0001

9. SPONSORING ORGANIZATION - NAME AND ADDRESS (If NRC, type "Same as above"; if contractor, provide NRC DIvision, Office or Region U.S. Nuclear Regulatory Commission, and mailing address.)

Office for Analysis and Evaluation of Operational Data

U.S. Nuclear Regulatory Commission

Washington, D.C. 20555-0001

10. SUPPLEMENTARY NOTES

11. ABSTRACT (200 words or less)

Tabletop exercises are held to discuss issues related to the response of organizations to an emergency event. This document describes in task format the planning, conduct, and reporting of lessons learned for a large interagency tabletop. A sample scenario, focus area, and discussion questions based on a simulated accident at a commercial nuclear power plant are provided.

exercise

tabletop

emergency response

excercise guidence

nuclear power 